\title{
Article \\ CFD-Simulink Modeling of the Inflatable Solar Dryer for Drying Paddy Rice
}

\author{
Ana Salvatierra-Rojas *(D), Iris Ramaj (D), Sebastian Romuli (D) and Joachim Müller (D) \\ Tropics and Subtropics Group (440e), Institute of Agricultural Engineering, University of Hohenheim, \\ 70599 Stuttgart, Germany; i.ramaj@uni-hohenheim.de (I.R.); Sebastian_Romuli@uni-hohenheim.de (S.R.); \\ joachim.mueller@uni-hohenheim.de (J.M.) \\ * Correspondence: Ana.SalvatierraRojas@uni-hohenheim.de or info440e@uni-hohenheim.de; \\ Tel.: +49-711-459-23114
}

\begin{abstract}
Small-scale farmers in developing Asian countries have minimal agricultural mechanisms available to them. In the Philippines, postharvest losses in rice production can reach about $36 \%$ in the drying process alone. Thus, the inflatable solar dryer (ISD) was developed through the collaboration of the University of Hohenheim, the International Rice Research Institute, and GrainPro Philippines Inc. Although the ISD was successfully tested with different agricultural products, further characterization of the ISD design is required for predicting the drying performance. To this end, the airflow behavior in the ISD was simulated using computational fluid dynamics (CFD) via ANSYS Fluent. Moreover, a thermal model was developed in MATLAB/Simulink by taking into account heat transfer in the heating area and coupled heat and mass transfer within the drying area. Three batches of drying experiments were performed and airflow measurements were taken inside the dryer to validate the models. The MATLAB/Simulink model was further used to predict the drying performance under various weather conditions spanning 10 years. The simulated temperatures and moisture content in the ISD showed high accuracy (mean absolute percentage error (MAPE) $<10 \%$ ) with the experimental data. The proposed dynamic model provides an efficient computational tool that can be applied to predict the drying performance and to optimize the ISD design.
\end{abstract}

Ramaj, I.; Romuli, S.; Müller, J. CFD-Simulink Modeling of the Inflatable Solar Dryer for Drying Paddy Rice. Appl. Sci. 2021, 11, 3118. https://doi.org/10.3390/app11073118

Academic Editor: Francesca Scargiali

Received: 5 March 2021

Accepted: 27 March 2021

Published: 1 April 2021

Publisher's Note: MDPI stays neutral with regard to jurisdictional claims in published maps and institutional affiliations.

\section{Introduction}

Rice is one of the most produced and consumed staple cereals globally. In the AsiaPacific region [1], 144 million rice farms, most of which are less than one hectare in area [2], produce over $90 \%$ of the world's production. Small-scale farmers in developing Asian countries have minimal agricultural mechanisms available to them. Almost all agricultural activities, including postharvest operations such as drying, are carried out manually. As a result, losses estimated during postharvest and processing stages across the rice value chain can range from $20 \%$ to $30 \%$ [3].

In the Republic of the Philippines, postharvest losses found in paddy rice can reach about $36 \%$ in the drying process alone [4,5]. Nowadays, most farmers still perform traditional sun drying practices. However, the farmers face several challenges when drying paddy rice due to high ambient relative humidity. This can be the case during unfavorable weather conditions or the rainy season, when there is lower solar radiation, or when sudden rainfall occurs. Under these conditions, the safe moisture content of $14 \%$ wet basis (w.b.) cannot be reached [6], and grains with high moisture contents are susceptible to attacks by microorganisms, insects, and pests [7]. Thus, decreasing postharvest losses is a realistic solution to increase the rice supply. Organizations and governments are supporting the development and the adaption of different technologies for small- and medium-scale farmers. Some examples are low-cost grain dryers [8], solar tunnel dryers [9], two-stage grain dryers $[10,11]$, and flat-bed dryers $[12,13]$. 
The dissemination of flat-bed dryers for paddy rice has been promoted since the 1970s in the Republic of the Philippines, but this technology was not well received by farmers. Some of the reasons behind the lack of adoption were the higher operating and maintenance costs compared to traditional sun drying practices [14]. As an alternative, in the 1980s, the solar tunnel dryer was tested for paddy rice at the International Rice Research Institute (IRRI) in the Republic at the Philippines headquarters. Despite the drying performance being promising, mixing the grains along the tunnel dryer was challenging $[9,15]$. Several interventions followed that offered alternative drying practices. However, in most instances, energy usage and loading capability restricted the acceptance of these technologies. Therefore, under this scenario, the inflatable solar dryer (ISD) was developed through a collaboration of the University of Hohenheim, the IRRI, and GrainPro Philippines Inc., who manufactured the dryer (trade name "Solar Bubble Dryer ${ }^{\mathrm{TM}}{ }^{\mathrm{T}}$ ) [16].

The ISD is a further development of the solar tunnel dryer, which was developed by the University of Hohenheim in the 1980s. The ISD design characteristics are: ease of transport and installation; simple operation compared to mechanical dryers; low maintenance since it is made of plastic material. Currently, the ISD has been successfully tested on paddy rice [16,17], amaranth leaves [18], mushrooms [19], and maize [20]. However, information on airflow distribution or heat and mass transfer of the ISD is still lacking.

According to Ghaffari and Mehdipour [21], four methods are widely used to model and analyze solar dryer systems. The first method is thermodynamic modeling using semiempirical equations. The second method is to establish differential equations that are solved by using computational fluid dynamics (CFD). The third method is based on statistical methods that use a series of experiments to develop empirical equations. The fourth method is the reacting engineering approach based on the chemical reaction subject to the drying process.

Researchers such as Hossain, et al. [22] have mostly used the first method for modeling solar tunnel dryer designs. Their study provided an approach for the simulation of a solar tunnel dryer, considering heat transfer and mass transfer equations to predict temperatures, product temperature, and moisture content. The numerical solution was programmed in BASIC language. A similar method was reported by Janjai, et al. [23]. The study generates a comprehensive numerical solution programmed in Compaq Visual Fortran. The results showed a good agreement between the simulated and the experimental values of temperatures and moisture content.

Esper [24] combines the first and second modeling methods where the program ESATAN was applied to solve the thermal model around the solar tunnel dryer. The simulated crop temperature and moisture content were in good agreement with the experimental data.

Based on recent developments in computer simulation developments, this study applied the first and the second methods for modeling the ISD. Therefore, this study aims: (i) to graphically portray the spatial distribution of airflow across the ISD by applying a computational fluid dynamic (CFD) approach and (ii) to ascertain the heat transfer in the heating area and coupled heat and mass transfer within the drying area using transient thermal modeling. The collaborative models were validated with field experiments and were used to simulate the ISD's performance when drying paddy rice drying under various weather conditions. Furthermore, this computational approach will allow specific development of the ISD design to dry different agricultural commodities with a reduced number of experiments.

\section{Materials and Methods}

\subsection{Inflatable Solar Dryer (ISD)}

2.1.1. Dryer Description

The design and function of the ISD have already been described in a previous study [16]. Since then, however, the materials used to build the ISD have been reduced to a black reinforced polyvinyl chloride film (PVC, $0.52 \mathrm{~mm}$ ) as the bottom layer, and a 
UV-stabilized transparent polyethylene film (PE, $150 \mu \mathrm{m})$ as the cover layer. A heavy-duty zipper connects the plastic films sewed along the edges of each plastic film, inflated by two axial flow ventilators of $72.6 \mathrm{~W}$ each, operated at $220 \mathrm{~V}$ (Runda Electronics CO., LTD, Shenzhen, China) (Figure 1).

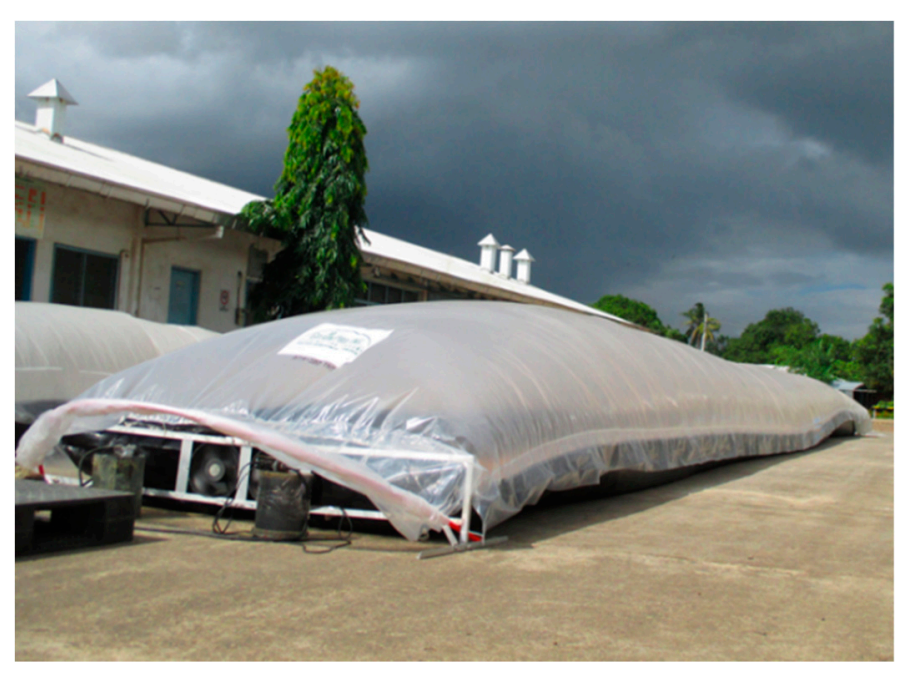

(a)

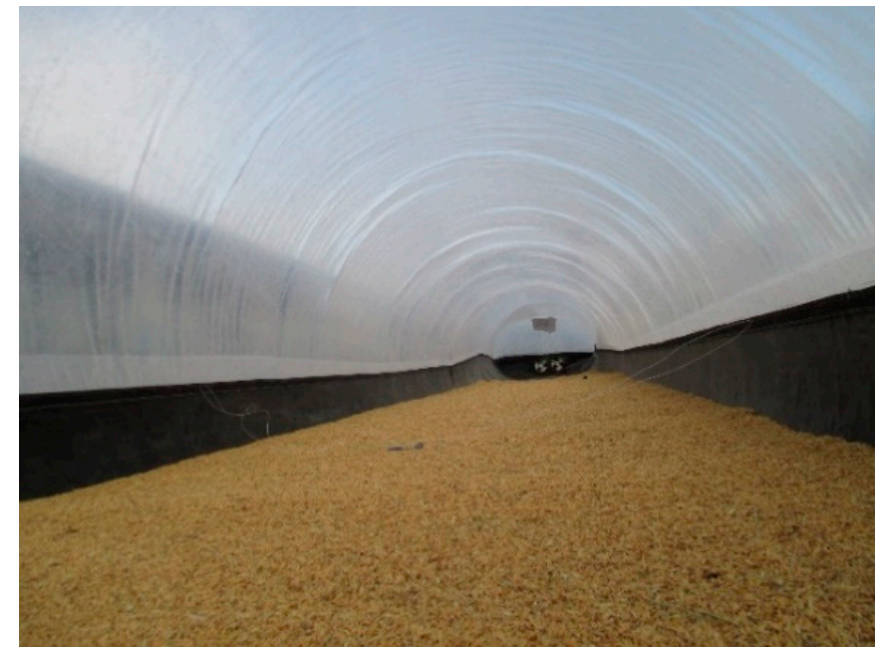

(b)

Figure 1. Inflatable solar dryer: (a) perspective view and (b) inside of the dryer.

\subsubsection{Field Experiments}

The experiments were performed at the International Rice Research Institute (IRRI) experimental station in Los Baños, Laguna, Republic of the Philippines $\left(14^{\circ} 11^{\prime} \mathrm{N}, 121^{\circ} 15^{\prime} \mathrm{E}\right.$, $21 \mathrm{~m}$ a.s.1.). Mixed rice varieties were used for the three batches of experiments during the rainy season between October and November 2013. The dryer was assembled on the ground. The two plastic films were unzipped to load the paddy rice. Then, the zipper of the dryer was closed, and the blowers were turned on to provide pressure to inflate the unit. The special roller provided for mixing the grains was pulled underneath the PVC film every hour between 8:00 and 17:00. After mixing, the moisture content was monitored. Ten grams of paddy rice was collected at three positions, as shown in Figure 2a. The samples were stored in plastic bags and transported to the IRRI laboratories. The moisture content was determined by the gravimetric method at $103 \pm 2{ }^{\circ} \mathrm{C}$ for $24 \mathrm{~h}$ [25]. The experiments were terminated when the rice reached a target moisture content of $14 \%$ wet basis $\left(\mathrm{MC}_{\mathrm{wb}}\right)$.

\subsubsection{Instrumentation for the Field Experiments and Velocity Measurements}

Solar radiation was measured using a pyranometer (CMP6, Kipp and Zonen, Delftechpark, Netherlands). Temperature and relative humidity capacity sensors (OM-EL-USB-2, Omega, Stamford, CT, USA) were placed inside the dryer at 1.5, 4, 14, $24 \mathrm{~m}$ from the inlet (Figure 2a). A further sensor was set to record the ambient temperature and relative humidity. The sensors were connected to a data logger (34970A, Agilent Technologies Inc., Loveland, CO, USA). The frequency of measurements was at five minutes intervals. A hot-wire anemometer (HHF42, Omega, Taipei, Taiwan) was used to measure the drying air velocity at the outlet position at one-hour intervals during the daytime.

To monitor the air velocity profile over the paddy rice, additional grid measurements were taken with the hot wire anemometer at nine positions along the dryer length and the six positions over the dryer width. The anemometer was fixed at $0.08 \mathrm{~m}$ above the paddy layer, facing the main airflow direction (Figure 2b). Contour plots were generated by kriging (Surfer ${ }^{\circledR}$ 19.1.189, Golden software, Golden, CO, USA). 


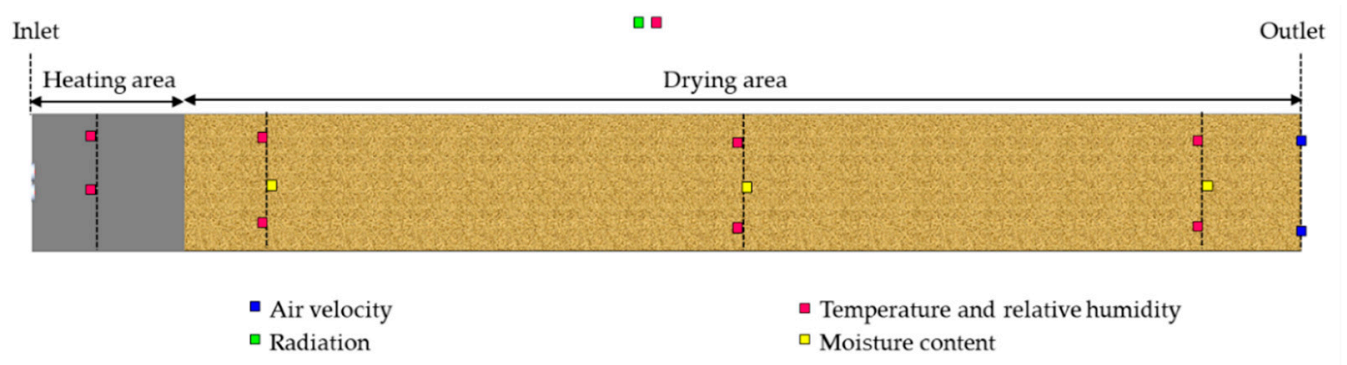

(a)

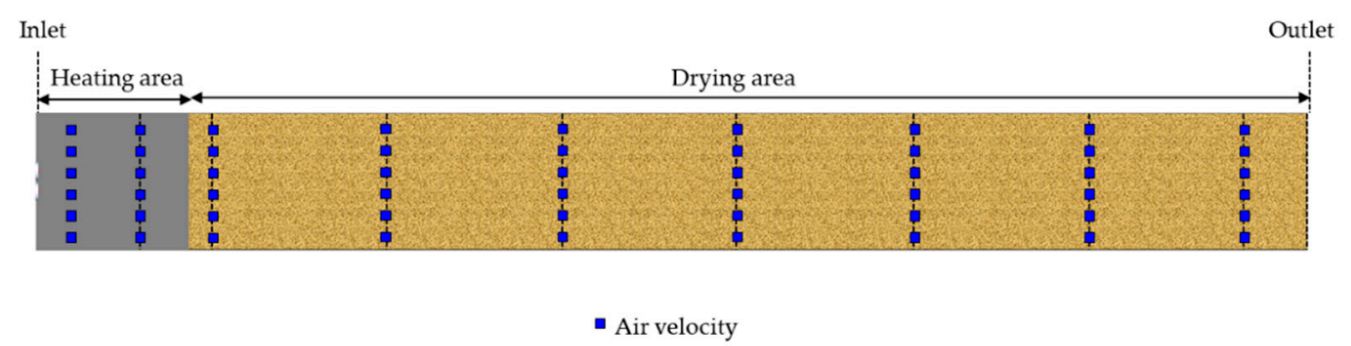

(b)

Figure 2. Position of measuring devices for (a) solar drying experiments (solar radiation, temperature, relative humidity, moisture content, and velocity) and (b) velocity measuring points across the dryer.

\subsection{Simulation of Airflow Distribution in the ISD}

\subsubsection{Governing Equations}

The differential form for a three-dimensional ISD design was simulated from the mass conservation presented according to [26]:

$$
\frac{\partial \rho_{\text {air }}}{\partial t}+\nabla \cdot\left(\rho_{\text {air }} \cdot \vec{v}\right)=0
$$

where $\vec{v}$ is the air velocity vector and $\rho_{\text {air }}$ is the density of air.

The Navier-Stokes equation is represented by the momentum conservation and it is written as [26]:

$$
\frac{\partial}{\partial t}\left(\rho_{\text {air }} \cdot \vec{v}\right)+\nabla \cdot\left(\rho_{\text {air }} \cdot \vec{v} \cdot \vec{v}\right)=-\nabla p+\nabla \cdot(\overline{\bar{\tau}})+\rho_{\text {air }} \cdot g+S_{m}
$$

where $p$ is the static pressure, $\overline{\bar{\tau}}$ is the Reynolds stress tensor, $g$ is the gravitational acceleration, and $S_{m}$ is the source term for momentum defined as [27]:

$$
S_{m}=\frac{150 \cdot(1-\epsilon)^{2}}{d_{k}^{2} \cdot \epsilon^{3}} \cdot \mu_{a i r} \cdot v_{\text {air }}+\frac{1.75 \cdot \rho_{\text {air }} \cdot(1-\epsilon)}{d_{k} \cdot \epsilon^{3}} \cdot v_{\text {air }}^{2}
$$

where $v_{\text {air }}$ is the velocity of the air, $\mu_{\text {air }}$ is the dynamic viscosity of air, $\in$ is the porosity of paddy rice bulk and $d_{k}$ is the kernel diameter. The paddy rice porosity and kernel diameter were 0.57 [28] and $1.99 \mathrm{~mm}$ [29]. According to ANSYS [30], the first term represents the viscous resistance, and the second term represents the inertial resistance. The corresponding values for each term were $1.634 \times 10^{7} \mathrm{~m}^{-2}$ and $2047 \mathrm{~m}^{-1}$. Symbols, terms, and units for each notation in all equations are described in the nomenclature list.

\subsubsection{Domain Description}

The 3D geometry of the ISD used for the simulations has a total length of $25 \mathrm{~m}$, where $3 \mathrm{~m}$ corresponds to the heating area and $22 \mathrm{~m}$ to the drying area (Figure 3 ). The inlet has a diameter of $0.25 \mathrm{~m}$ for each blower. Likewise, the outlets have diameters of $0.25 \mathrm{~m}$. The 
dryer's maximum height reached $1 \mathrm{~m}$, and the paddy rice layer was set to a thickness of $0.04 \mathrm{~m}$.

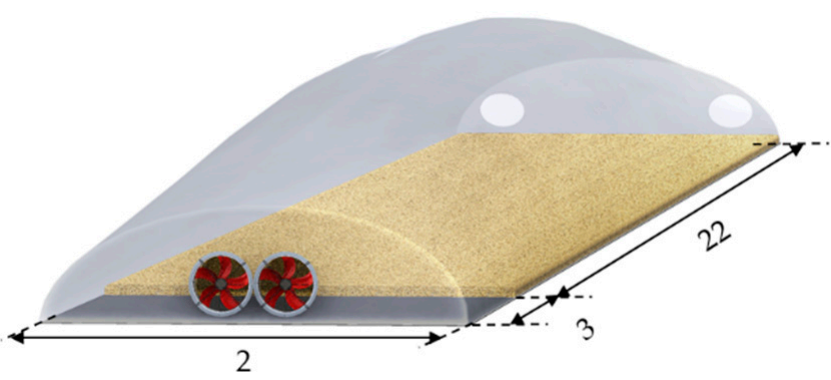

(a)

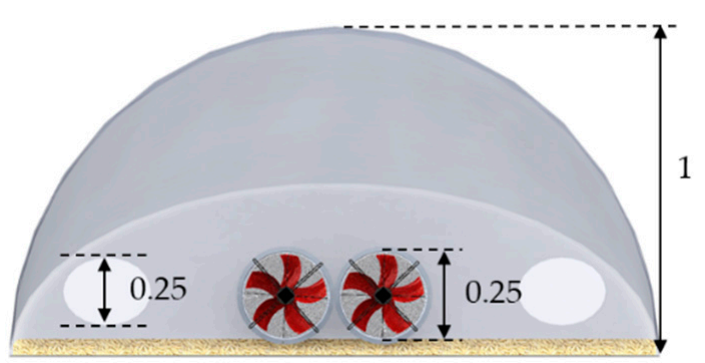

(b)

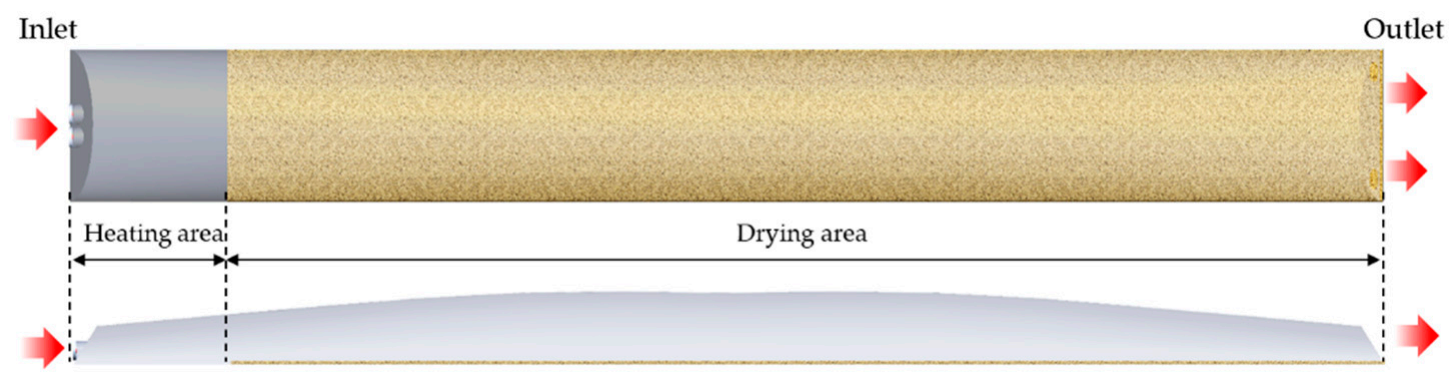

(c)

Figure 3. Inflatable solar dryer (ISD) computational geometry: (a) isometric, (b) front, (c) top and side view (dimensions are shown in $\mathrm{m})$.

The fluid volume of the dryer was meshed using the ANSYS Workbench meshing tool. The mesh quality was assessed by ensuring that all elements' skewness and element quality fell within the optimal ranges [31]. A grid independence study was performed with four mesh refinements (mesh I—813490, mesh II - 1072594, mesh III-1572592, and mesh IV-2498880). Finally, mesh III was selected as a good compromise between accuracy and computation time [32].

\subsubsection{CFD Model Simulation}

The simulation of the airflow distribution in the ISD was carried out using ANSYS Fluent 19.1 (ANSYS Workbench, ANSYS, Inc., Canonsburg, PA, USA) installed on a HP Z420 Workstation (Hewlett-Packard, Palo Alto, CA, USA) with an Intel Xeon CPU E5-1660 $3.30 \mathrm{GHz}$ processor and RAM $32 \mathrm{~GB}$. The simulations were performed in a steady state and the k-erealizable turbulence model was used with enhanced wall treatment. The governing equations were computed by applying a pressure-based segregated solver and the default under-relaxation factors set as solution controls. The materials used were subdivided into the fluid (drying air across the ISD) and the solid (paddy rice). The properties of incompressible gas were applied. Based on the experimental data, the calculated inlet velocity was $5 \mathrm{~m} \mathrm{~s}^{-1}$. The assumptions considered in the ISD simulation were nonadiabatic and no-slip walls, as well as no shrinkage or deformation of paddy rice kernels during drying. The paddy rice bulk was considered as a porous medium.

\subsection{Mathematical Modeling of the ISD}

The ISD is divided into segments of one $m$ in the direction of the airflow. The mathematical model for the ISD was developed, taking into account heat transfer in the heating area and a coupled heat and mass transfer within the drying area. The drying of paddy 
rice in the ISD was modeled following the approach of Hossain, et al. [22]. A schematic diagram of energy transfers inside the inflatable solar dryer is shown in Figure 4, and the following heat and mass balances are formulated.

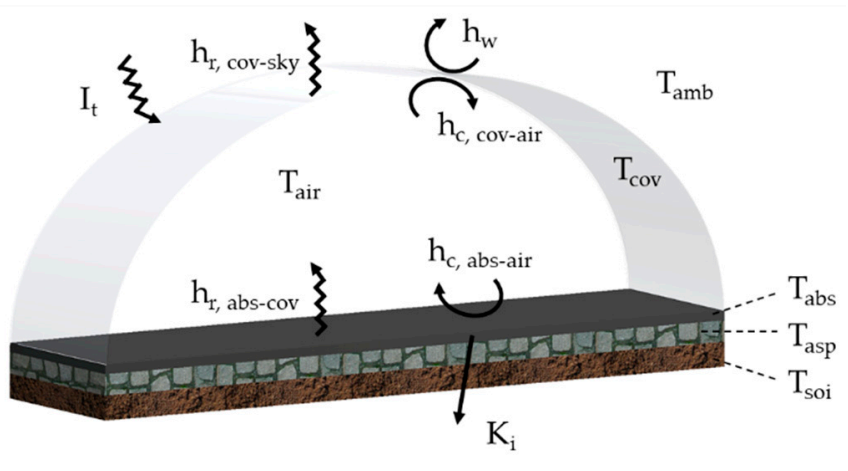

(a)

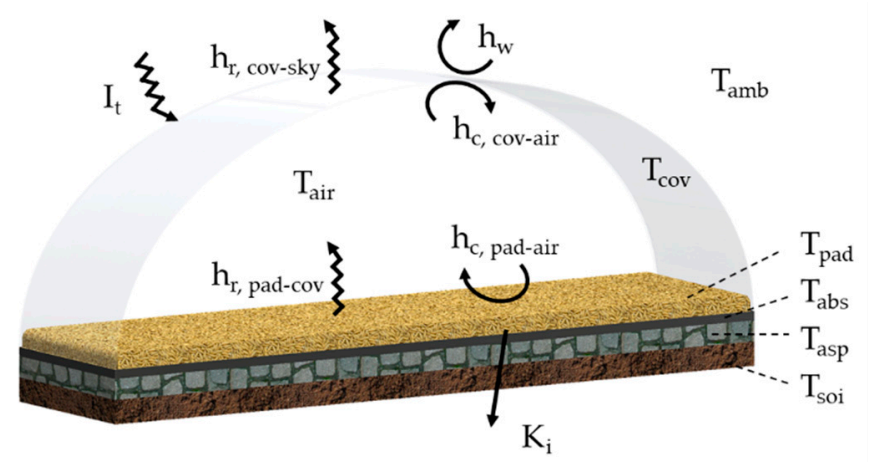

(b)

Figure 4. Schematic diagram of heat balances in the (a) heating area and (b) drying area of the ISD ( - radiation, -convection, and $\rightarrow$ - conduction).

\subsubsection{Energy Balance of the Cover for the Heating Area}

Figure 4 shows the energy equilibration of a control volume in the heating area. The energy balance of the cover is given as:

$$
T_{c o v}=\frac{\alpha_{c o v} \cdot\left(1+\tau_{c o v} \cdot \rho_{a b s}\right) \cdot I_{t}+h_{w} \cdot T_{a m b}}{h_{w}+h_{c, c o v-a i r}+h_{r, c o v-s k y}+h_{r, a b s-c o v}}+\frac{h_{c, c o v-a i r} \cdot T_{a i r}+h_{r, c o v-s k y} \cdot T_{s k y}+h_{r, a b s-c o v} \cdot T_{a b s}}{h_{w}+h_{c, c o v-a i r}+h_{r, c o v-s k y}+h_{r, a b s-c o v}}
$$

where $T_{c o v}$ is the temperature of the cover, $T_{a m b}$ is the temperature of the ambient conditions, $T_{a i r}$ is the temperature of the air, $T_{s k y}$ is the temperature of the sky, $T_{a b s}$ is the temperature of the absorber, $h_{w}, h_{c, c o v-a i r}, h_{c, a b s-a i r}$ are the convection heat transfer coefficients between the cover and the air outside of the heating area due to wind, the cover and the air inside the heating area, and the surface of the heating area and the air inside, respectively. Additionally, $h_{r, a b s-a i r}$ and $h_{r, c o v-a i r}$ are the radiative transfer coefficients between the cover and the air outside of the heating area, and the absorber and the cover, respectively. $\alpha_{c o v}$ is the absorbance of the cover, $\tau_{c o v}$ is the transmittance of the cover, $\rho_{a b s}$ is the reflectance of the absorber and $I_{t}$ is the instantaneous solar radiation. Complementary information on the heat transfer coefficients and how to determine them are provided in Appendix A.

\subsubsection{Energy Balance of the Absorber for the Heating area}

The energy balance corresponding to the heating area relates to the change over time of the energy stored in the absorber:

$$
T_{a b s}=\frac{\frac{\alpha_{a b s} \cdot \tau_{c o v} \cdot I_{t}}{1-\left(1-\alpha_{a b s}\right) \cdot \rho_{a b s}}+h_{c, a b s-a i r} \cdot T_{a i r}}{h_{c, a b s-a i r}+h_{r, s k y-a b s}+h_{r, a b s-c o v}+K_{p a d-a s p}}+\frac{h_{r, s k y-a b s} \cdot T_{s k y}+h_{r, a b s-c o v} \cdot T_{c o v}+K_{a b s-a s p} \cdot T_{a s p}}{h_{c, a b s-a i r}+h_{r, s k y-a b s}+h_{r, a b s-c o v}+K_{a b s-a s p}}
$$

where $T_{a s p}$ is the temperature of the asphalt and $K_{a b s-a s p}$ is the thermal conductance from the absorber to the asphalt.

\subsubsection{Energy Balance of the Airflow for the Heating Area}

The energy balance in the air stream in the collector is given as:

$$
\rho_{a i r} \cdot \delta_{a i r} \cdot v_{a i r} \cdot c_{a i r} \cdot \frac{\partial T_{a i r}}{\partial x}=h_{c, c o v-a i r} \cdot\left(T_{c o v}-T_{a i r}\right)+h_{c, a b s-a i r} \cdot\left(T_{a b s}-T_{a i r}\right)
$$

where $\delta_{a i r}$ is the layer thickness of the air, $v_{a i r}$ is the air velocity, $c_{a i r}$ is the air specific heat of air, and $\partial T_{\text {air }} / \partial x$ is the temperature gradient in the direction of the airflow. 
The radiative and convective heat transfer coefficients were taken from Hossain, et al.'s work [22]. The convective heat transfer coefficient was computed as:

$$
h_{c, \text { cov-air }}=h_{c, a b s-a i r}=h_{c}=\frac{N u \cdot \lambda_{\text {air }}}{D_{h}}
$$

where $\lambda_{\text {air }}$ is thermal conductivity of the air, $D_{h}$ is the hydraulic diameter, and $N u$ is the Nusselt number. The Reynolds number for a turbulent regime was calculated according to Cengel [33].

$$
N u=0.03808 \cdot \operatorname{Re}^{0.8} \cdot \operatorname{Pr}^{1 / 3}
$$

where $P r$ is the Prandtl number and $R e$ is the Reynolds number, which is given according to [33]:

$$
R e=\frac{v_{a i r} \cdot L_{c}}{v_{\text {air }}}
$$

where $L_{\mathcal{C}}$ is the characteristic length of the geometry and $v_{a i r}$ is the kinematic viscosity of air.

\subsubsection{Energy Balance of the Cover in the Drying Area}

According to Figure 4, the energy balance for the cover in the drying area results from the convective heat exchange between the cover and the heat transport by the drying air, which flows between the cover and the paddy rice in the drying area:

$$
T_{c o v}=\frac{\alpha_{c o v} \cdot\left(1+\tau_{c o v} \cdot \rho_{p a d}\right) \cdot I_{t}+h_{w} \cdot T_{a m b}+h_{c, c o v-a i r} \cdot T_{a i r}+h_{r, c o v-s k y} \cdot T_{s k y}+h_{r, p a d-c o v} \cdot T_{p a d}}{h_{w}+h_{c, c o v-a i r}+h_{r, c o v-s k y}+h_{r . p a d-c o v}}
$$

where $T_{p a d}$ is the temperature of paddy rice and $\rho_{\text {pad }}$ is the reflectance of paddy rice.

As found in a previous study [34], the reflectance is dependent on the zenith angle $(\theta)$ :

$$
\rho_{\text {pad }}=0.2704+1.816 \cdot 10^{-5} \cdot e^{0.1761 \cdot \theta}
$$

\subsubsection{Energy Balance of the Paddy Rice in the Drying Area}

The change over time of the energy stored in the product results from the radiant energy on the product, the convective heat exchange between the product and the drying air, the radiant heat exchange with the cover, the environment, and the thermal losses to the ground as well as the energy required in the unit of time to evaporate the moisture. The energy balance is presented as:

$$
\begin{aligned}
\frac{\partial T_{p a d}}{\partial t}= & \frac{\frac{\alpha_{p a d} \cdot \tau_{c o v} \cdot I_{t}}{1-\left(1-\alpha_{p a d}\right) \cdot \rho_{p a d}}+\rho_{p a d} \cdot \delta_{p a d}\left(L_{p a d}+\left(c_{v a p}-c_{\text {liq }}\right) \cdot T_{p a d}\right) \cdot \frac{\partial M}{\partial t}+h_{c, p a d-a i r} \cdot\left(T_{a i r}-T_{p a d}\right)}{\rho_{\text {pad }} \cdot \delta_{\text {pad }} \cdot\left(c_{\text {pad }}+c_{\text {liq }} \cdot M\right)} \\
& +\frac{h_{r, p a d-s k y} \cdot\left(T_{\text {sky }}-T_{p a d}\right)+h_{r, p a d-c o v} \cdot\left(T_{c o v}-T_{p a d}\right)+K_{p a d-a b s} \cdot\left(T_{a b s}-T_{p a d}\right)}{\rho_{p a d} \cdot \delta_{p a d} \cdot\left(c_{p a d}+c_{\text {liq }} \cdot M\right)}
\end{aligned}
$$

where $\rho_{\text {pad }}$ is the bulk density of paddy rice, $\delta_{\text {pad }}$ is the thickness of the paddy rice bulk, $c_{\text {vap }}$ is the specific heat of water vapor, $c_{l i q}$ is the specific heat of liquid, $c_{\text {pad }}$ is the specific heat of paddy rice, $K_{\text {pad-abs }}$ is the thermal conductance from paddy rice to absorber, $M$ is the moisture content dry basis (d.b.), $L_{p a d}$ is the latent heat of paddy rice [35] and $\alpha_{\text {pad }}$ is the absorbance of paddy rice.

\subsubsection{Energy Balance of the Airflow in the Drying Area}

The energy balance for the moist air in the drying area is given as:

$$
\rho_{\text {air }} \cdot \delta_{\text {air }} \cdot v_{\text {air }} \cdot\left(c_{\text {pad }}+c_{\text {vap }} \cdot H\right) \cdot \frac{\partial T_{\text {air }}}{\partial x}=h_{c, \text { cov-air }} \cdot\left(T_{\text {cov }}-T_{\text {air }}\right)+h_{c, \text { pad-air }} \cdot\left(T_{\text {pad }}-T_{\text {air }}\right)
$$

where $H$ is the humidity ratio of air inside the dryer. The heat transfer coefficients are provided in Appendix A. 


\subsubsection{Energy Balance of the Bottom Layers for the Heating and Drying Area}

As the ISD does not have an insulation material, the influence of the ground layers $i$ (asphalt, soil, and absorber) is considered in the model following our previous research [34], in which the sun drying practice was modeled. The energy balance of the bottom layers under the ISD is driven by heat conduction. Figure 4 shows the thermal network across the bottom layers. The rate of thermal energy flow into the bottom layers is given as:

$$
C_{i} \cdot \frac{d T_{i}}{d t}=K_{i} \cdot\left(T_{\text {top }}-T_{i}\right)+K_{i} \cdot\left(T_{\text {bottom }}-T_{i}\right)
$$

where $T_{i}$ is the material temperature of the respective layer $i, C_{i}$ is the thermal capacity of the material, calculated by the specific heat capacity $c_{i}$, and the thickness $\delta_{i}$ of the layer $i$ :

$$
C_{i}=c_{i} \cdot \delta_{i}
$$

The thermal conductance $K_{i}$ is given as:

$$
K_{i}=\frac{\lambda_{i}}{\frac{1}{2} \cdot \delta_{i}}
$$

where $\lambda_{i}$ is the thermal conductivity of the material $i$ (asphalt, soil, and absorber). The temperatures $T_{\text {top }}$ and $T_{\text {bottom }}$ of the layers are known boundary conditions between the layers and are given as:

$$
\begin{gathered}
T_{\text {top }}=\frac{K_{i} \cdot T_{i}+K_{i+1} \cdot T_{i+1}}{K_{i}+K_{i+1}} \\
T_{\text {bottom }}=\frac{K_{i} \cdot T_{i}+K_{i-1} \cdot T_{i-1}}{K_{i}+K_{i-1}}
\end{gathered}
$$

\subsubsection{Mass Balance}

The moisture evaporating from the crop in the drying area is absorbed by the air. This causes a change in the enthalpy of the air, which can be described by the energy and mass balance. The rate of moisture transfer between the product and the surrounding air is expressed as:

$$
\rho_{\text {air }} \cdot \delta_{\text {air }} \cdot v_{\text {air }} \cdot \frac{\partial H}{\partial x} \cdot d x \cdot d t=-\rho_{\text {pad }} \cdot d x \cdot \frac{\partial M}{\partial t} \cdot d t
$$

where $\partial H / \partial x$ is the humidity ratio and $\partial M / \partial t$ is the drying rate gradient in the direction of the airflow. The drying rate is calculated as:

$$
\frac{\partial M}{\partial t}=-k \cdot\left(M-M_{e}\right)
$$

where $M_{e}$ is the equilibrium moisture content and $k$ is the drying constant. The calculation of $M_{e}$ was obtained from the Chung-Pfost equation using the coefficients given by Iguaz and Vírseda [36]:

$$
M_{e}=\left(-\frac{1}{0.179}\right) \cdot \ln \left(\left(-\frac{\left(\left(T_{\text {air }}-273.15\right)+16.912\right)}{277.091}\right) \cdot \ln (\varphi)\right)
$$

where $\varphi$ is the relative humidity of the drying air.

The drying constant was obtained from paddy rice drying experiments conducted under controlled conditions. This experiment was necessary as no other paper on the subject had been reported. The drying experiments were carried out using the overflow chamber of a high-precision laboratory dryer from the Institute of Agricultural Engineering, University of Hohenheim in Stuttgart (Germany). The experimental system has been previously described in detail by Udomkun, et al. [37]. The drying experiments were conducted at air temperatures of $30,40,50$, and $60^{\circ} \mathrm{C}$ and humidity ratio of $0.020 \mathrm{~kg} \mathrm{~kg}^{-1}$. 
The paddy rice was filled in a tray of $0.30 \times 0.30 \times 0.04 \mathrm{~m}$ having a layer thickness of $0.04 \mathrm{~m}$. The paddy rice was dried to the equilibrium moisture content. The experiments were performed per triplicate for each drying condition.

The drying equation was built following three steps. The first step corresponds to the computation of the moisture ratio from the drying experiments; the second step was to obtain the drying coefficient $(k)$ per experiment attributed to the Newton model. The third step was to fit the drying coefficient of the different experimental conditions by using an Arrhenius type equation:

$$
k=4758 \cdot e^{-\frac{2987}{T_{\text {air }}}}
$$

The goodness of fit for Equation (22) resulted in a coefficient of determination $\left(R^{2}\right)$ of 0.87 and a root mean square error (RMSE) of $0.10 \mathrm{~h}^{-1}$.

\subsubsection{Solution Procedure}

The partial differential equations generated for the heating area and the drying area describe heat and heat-mass transfer over small time increments. The numerical integration with respect to time and position can be solved using the finite difference method [22]. The transformation from the physical domain to the computational domain was obtained by creating a numerical simulation model of algebraic equations in one dimension. The finite volume differences of formulated heat and mass balances were replaced by the derivatives in the differential equations.

The drying air temperature given in Equation (6) was calculated over the finite distance $(\Delta x)$ to give the change in air temperature in the heating area $\left(\Delta T_{\text {air }}\right)$ as:

$$
\frac{\partial T_{a i r}}{\partial x}=\frac{h_{c, c o v-a i r} \cdot\left(T_{c o v}-T_{a i r}\right)+h_{c, a b s-a i r} \cdot\left(T_{a b s}-T_{a i r}\right)}{\rho_{a i r} \cdot \delta_{\text {air }} \cdot v_{\text {air }} \cdot c_{\text {air }}}
$$

Introducing auxiliary terms $A_{1}$ and $A_{2}$ and noting $h_{\mathcal{c}}$ for $h_{c, c o v-a i r}$ and $h_{c, a b s-a i r}$ :

$$
A_{1}=\frac{2 \cdot h_{c}}{\rho_{\text {air }} \cdot \delta_{\text {air }} \cdot v_{\text {air }} \cdot c_{\text {air }}} \quad A_{2}=\frac{T_{c o v}+T_{\text {air }}}{2}
$$

leads to:

$$
\Delta T_{\text {air }}=T_{\text {air } \_} i-T_{\text {air } r_{-} i-1}=\left(A_{2}-T_{a i r_{-} i-1}\right) \cdot\left(1-e^{-A_{1} \cdot \Delta x}\right)
$$

The solution for the energy balance of the air in the drying area given in Equation (13) is solved as:

$$
\frac{\partial T_{\text {air }}}{\partial x}=-A_{3} \cdot T_{\text {air }}+A_{4}
$$

where auxiliary terms $A_{3}$ and $A_{4}$ are:

$$
A_{3}=\frac{2 \cdot h_{c}}{\rho_{\text {air }} \cdot \delta_{\text {air }} \cdot v_{\text {air }} \cdot\left(c_{\text {air }}+c_{\text {vap }} \cdot H\right)} \quad A_{4}=\frac{T_{\text {cov }}+T_{\text {air }}}{\rho_{\text {air }} \cdot \delta_{\text {air }} \cdot v_{\text {air }} \cdot\left(c_{\text {air }}+c_{\text {vap }} \cdot H\right)}
$$

leading to:

$$
T_{\text {air } 2}=\frac{A_{4}}{A_{3}}+\left(T_{\text {air } 1}-\frac{A_{4}}{A_{3}}\right) \cdot e^{-A_{3} \cdot \Delta t}
$$

The temperature of paddy rice generated in Equation (12) can be solved as:

$$
\frac{\partial T_{p a d}}{\partial t}=-A_{5} \cdot T_{p a d}+A_{6}
$$

with auxiliary terms $A_{5}$ and $A_{6}$ : 


$$
\begin{aligned}
& A_{5}=\frac{\frac{\alpha_{\text {pad }} \cdot \tau_{c o v} \cdot I_{t}}{1-\left(1-\alpha_{\text {pad }}\right) \cdot \rho_{\text {pad }}}+\rho_{\text {pad }} \cdot \delta_{\text {pad }} \cdot L_{\text {pad }} \cdot \frac{\partial M}{\partial t}}{\rho_{\text {pad }} \cdot \delta_{\text {pad }} \cdot\left(c_{\text {pad }}+c_{\text {liq }} \cdot M\right)} \\
& +\frac{h_{c, p a d-a i r} \cdot T_{a i r}+h_{r, p a d-s k y} \cdot T_{\text {sky }}+h_{r, p a d-c o v} \cdot T_{c}+K_{\text {pad-abs }} \cdot T_{a b s}}{\rho_{\text {pad }} \cdot \delta_{\text {pad }} \cdot\left(c_{\text {pad }}+c_{\text {liq }} \cdot M\right)} \\
& A_{6}=-\frac{-\rho_{\text {pad }} \cdot \delta_{\text {pad }} \cdot\left(c_{\text {vap }}-c_{\text {liq }}\right) \cdot \frac{\partial M}{\partial t}+h_{c, p a d-a i r}+h_{r, p a d-s k y}+h_{r, p a d-c o v}+K_{\text {pad-abs }}}{\rho_{\text {pad }} \cdot \delta_{\text {pad }} \cdot\left(c_{\text {pad }}+c_{\text {liq }} \cdot M\right)}
\end{aligned}
$$

leading to:

$$
T_{\text {pad } 2}=\frac{A_{6}}{A_{5}}+\left(T_{p a d 1}-\frac{A_{6}}{A_{5}}\right) \cdot e^{-A_{5} \cdot \Delta t}
$$

The rate of change of moisture content inside the dryer is represented in the finite difference form according to Bala [35]:

$$
\Delta M=\frac{-k \cdot\left(M-M_{e}\right) \cdot \Delta t}{1+\frac{k}{2} \cdot \Delta t}
$$

The change of humidity solution can be calculated as:

$$
\Delta H=-\left(\frac{\rho_{\text {pad }}}{b \cdot \rho_{\text {air }} \cdot \delta_{\text {air }} \cdot v_{\text {air }}}\right) \cdot\left(\frac{\Delta M}{\Delta t}\right) \cdot \Delta x
$$

Table 1 presents the material properties of the ISD, the paddy rice, and the ground layers used for the MATLAB/Simulink ${ }^{\circledR}$ model.

Table 1. Properties of the materials.

\begin{tabular}{ccc}
\hline Description & Value & Unit \\
\hline Cover [38] & & \\
Density $\rho_{\text {cov }}$ & 920.0 & $\mathrm{~kg} \mathrm{~m}^{-3}$ \\
Specific heat $c_{\text {cov }}$ & 2200.0 & $\mathrm{~J} \mathrm{~kg}^{-1} \mathrm{~K}^{-1}$ \\
Thermal conductivity $\lambda_{\text {cov }}$ & 0.24 & $\mathrm{~W} \mathrm{~m}^{-1} \mathrm{~K}^{-1}$ \\
\hline Absorber [38] & & \\
Density $\rho_{a b s}$ & 1300.0 & $\mathrm{~kg} \mathrm{~m}^{-3}$ \\
Specific heat $c_{a b s}$ & 1500.0 & $\mathrm{~J} \mathrm{~kg}^{-1} \mathrm{~K}^{-1}$ \\
Thermal conductivity $\lambda_{\text {abs }}$ & 0.14 & $\mathrm{~W} \mathrm{~m}^{-1} \mathrm{~K}^{-1}$ \\
\hline Paddy rice [28] & & \\
Density $\rho_{\text {pad }}$ & 609.0 & $\mathrm{~kg} \mathrm{~m}^{-3}$ \\
Specific heat $c_{\text {pad }}$ & 2000.0 & $\mathrm{~J} \mathrm{~kg}^{-1} \mathrm{~K}^{-1}$ \\
Thermal conductivity $\lambda_{\text {pad }}$ & 0.12 & $\mathrm{~W} \mathrm{~m}^{-1} \mathrm{~K}^{-1}$ \\
\hline Asphalt [39] & & \\
Density $\rho_{a s p}$ & 2282.0 & $\mathrm{~kg} \mathrm{~m}^{-3}$ \\
Specific heat $c_{a s p}$ & 959.0 & $\mathrm{~J} \mathrm{~kg}^{-1} \mathrm{~K}^{-1}$ \\
Thermal conductivity $\lambda_{\text {asp }}$ & 1.30 & $\mathrm{~W} \mathrm{~m}^{-1} \mathrm{~K}^{-1}$ \\
\hline Soil [40] & & \\
Density $\rho_{\text {soi }}$ & 2650.0 & $\mathrm{~kg} \mathrm{~m}^{-3}$ \\
Specific heat $c_{\text {soi }}$ & 870.0 & $\mathrm{~J} \mathrm{~kg} \mathrm{~K}^{-1}$ \\
Thermal conductivity $\lambda_{\text {soi }}$ & 2.50 & $\mathrm{~W} \mathrm{~m} \mathrm{~K}^{-1}$ \\
\hline
\end{tabular}

MATLAB/Simulink ${ }^{\circledR}$ 2019a (MathWorks Inc., Natick, MA, USA) was used to compute the temperatures and the moisture content behavior of the paddy rice drying inside the ISD. The lumped equations are a set of partial differential equations that are converted to coupled ordinary equations to solve using Simulink graphical interface [41]. The flowchart of the solution is illustrated in Figure 5. The coefficient of determination $\left(R^{2}\right)$, the root mean 
square error (RMSE), and mean absolute percentage error (MAPE) were used to assess the accuracy of prediction models.

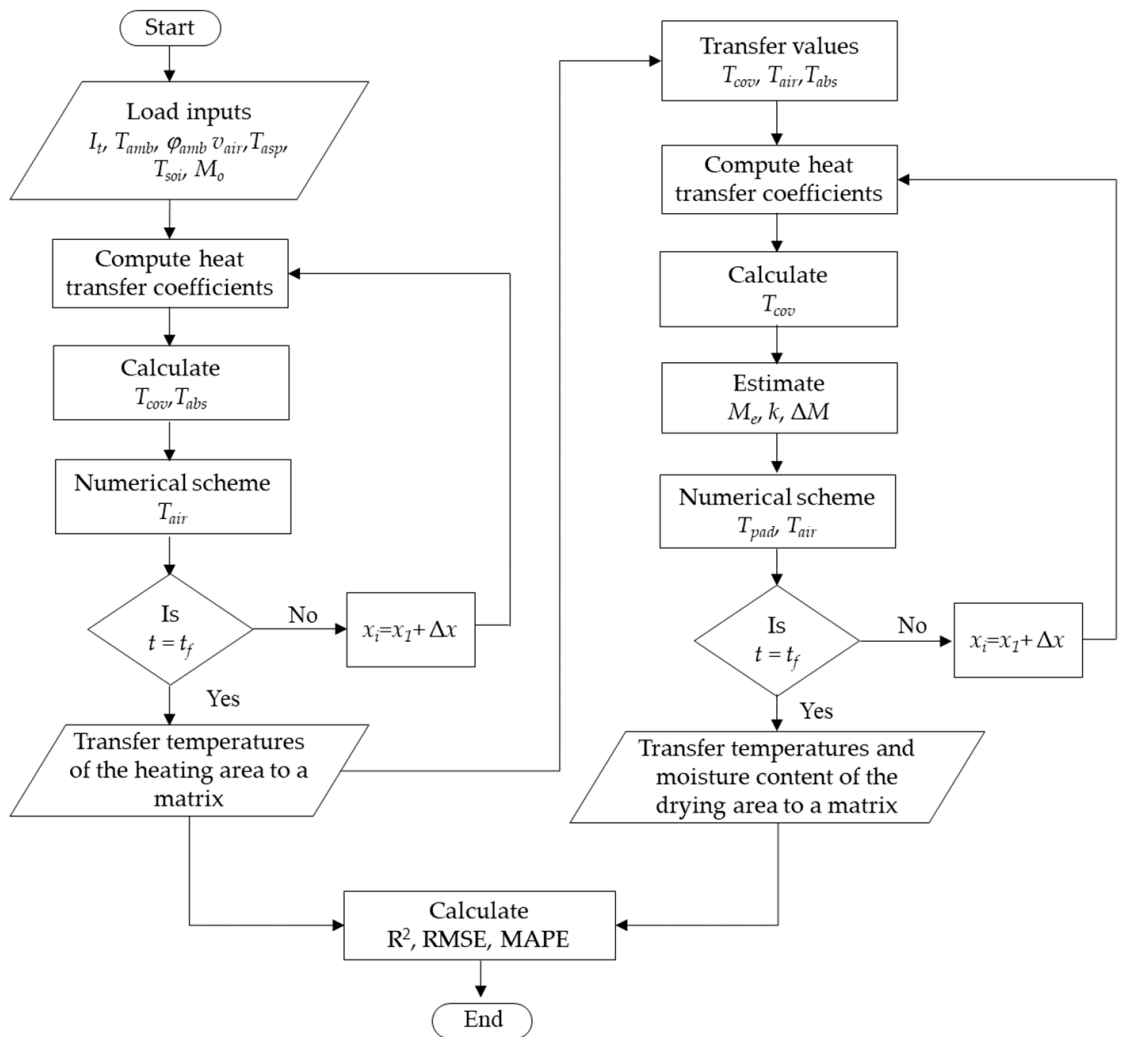

Figure 5. Simulation procedure flowchart.

\subsection{Model Implementation}

The weather data were collected from the weather station at the experimental station of the International Rice Research Institute in Los Baños, Laguna, Republic of the Philippines at $14^{\circ} 11^{\prime} \mathrm{N}, 121^{\circ} 15^{\prime} \mathrm{E}$. The annual weather records from 2008 to 2017 were collected from the weather station every $15 \mathrm{~min}$. Ambient temperature, relative humidity, and daily solar radiation data were averaged (see Figure 6). The weather data were used for the model implementation corresponding to the peak harvest season for the dry season (April and May) and the rainy season (October and November). Table 2 shows the initial values for the ISD model in MATLAB/Simulink.

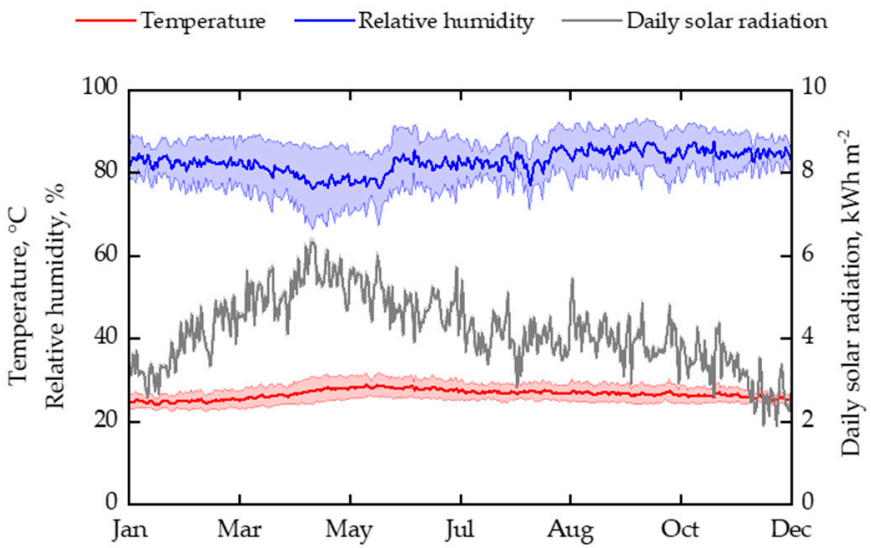

Figure 6. Annual weather data from the weather station at the International Rice Research Institute (IRRI) (averaged values 2008-2017). 
Table 2. Initial values for the ISD model.

\begin{tabular}{lcc}
\hline \multicolumn{1}{c}{ Parameter } & Dry Season & Rainy Season \\
\hline Moisture content w.b., \% & 18.0 & 22.5 \\
Humidity ratio, $\mathrm{kg} \mathrm{kg}^{-1}$ & 0.015 & 0.020 \\
Drying time, h & 32 & 48 \\
\hline
\end{tabular}

\section{Results}

\subsection{CFD Simulations}

\subsubsection{Simulation of the Airflow Distribution}

The simulation of the airflow pattern in the inflatable solar dryer (ISD) is shown in Figure 7, where the airflow direction travels from left to right. Figure 7a shows the vortex caused by the fans located at the inlet. The vortex covers the first meters of the ISD, where the air velocity is the highest (Figure $7 \mathrm{~b}$ ). Furthermore, the airflow in the drying area forms a transition zone, where the airflow presents an even distribution over the paddy rice. However, backflow was observed one meter before exiting the dryer. The turbulence model $k-\epsilon$ predicted the presence of the air turbulence in the area located at 3 to $4 \mathrm{~m}$ from the fans well, creating a recirculation pattern.
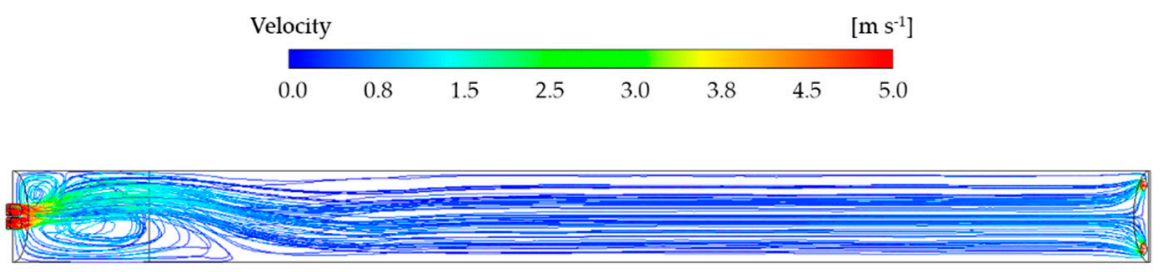

(a)

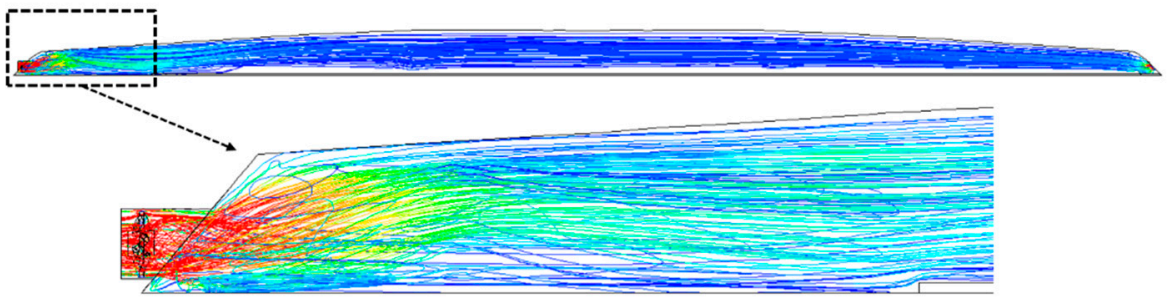

(b)

Figure 7. 3D streamlines of airflow in the ISD: (a) top view and (b) side view with zoomed view of the heating area.

\subsubsection{Validation of the CFD Model}

A contour plot was used to compare the CFD simulation and the experimental values and to analyze the airflow distribution over the paddy rice (Figure 8). The simulated results were consistent with Figure 7 . Thus, the airflow velocity was higher at the left side. It can be seen that the air velocity profile at $0.08 \mathrm{~m}$ decreased in the heating area from 5.0 to $0.5 \mathrm{~m} \mathrm{~s}^{-1}$, and the velocity in the drying area was around $0.1 \mathrm{~m} \mathrm{~s}^{-1}$.

Figure 9 shows the computational and experimental velocities over the ISD's length. The results indicate that air velocity decreased along the dryer length and that air velocity magnitude in the $\mathrm{x}$-direction at $0.08 \mathrm{~m}$ above the paddy rice verifies the computational results with the experimental data. The comparison with the computed and experimental data revealed a good correlation, with a $\mathrm{R}^{2}$ of 0.78 and a RMSE of $0.72 \mathrm{~m} \mathrm{~s}^{-1}$. 

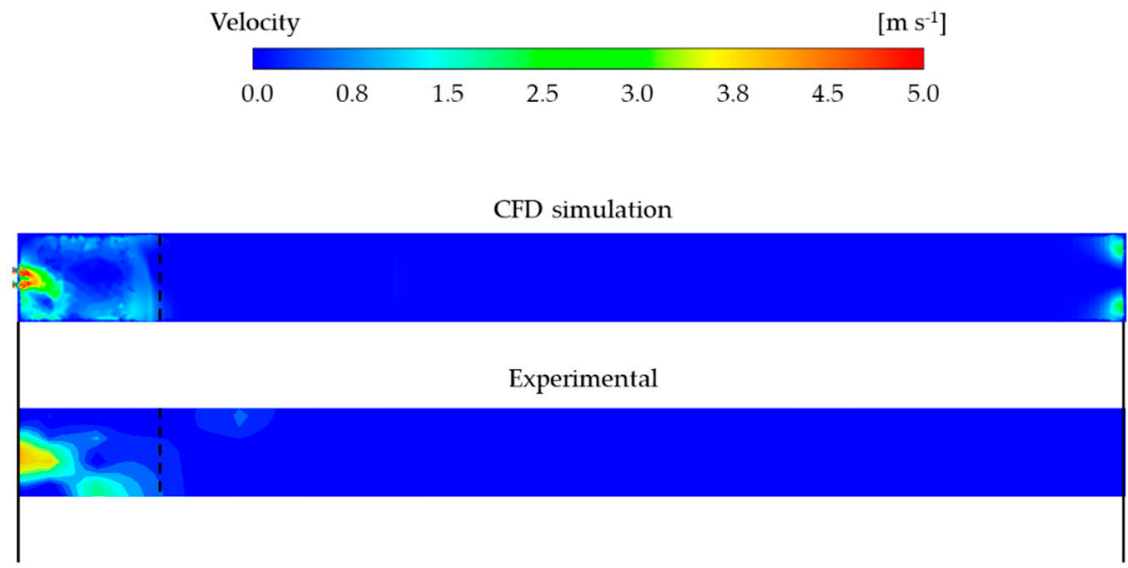

Inlet

Outlet
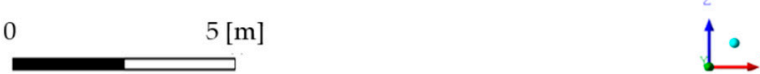

Figure 8. Contour plots of the simulated and experimental airflow distribution at the height of $0.08 \mathrm{~m}$ across the ISD.

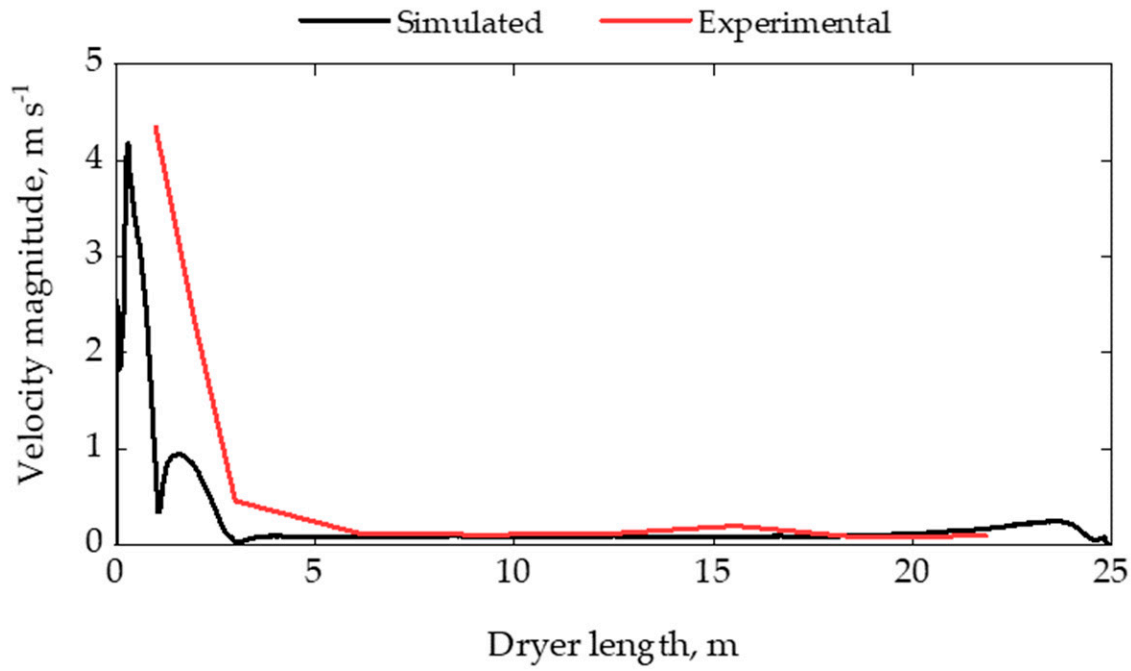

Figure 9. Simulated and experimental air velocity along the centerline at the height of $0.08 \mathrm{~m}$ over the ISD length.

\subsection{Validation of the Drying Model}

3.2.1. Simulation of the Air Temperature during the Drying Process

Figure 10 presents the solar radiation, the ambient temperature, and the relative humidity during the three experimental batches of solar drying of paddy rice in the ISD. The solar radiation during the rainy season shows higher variations due to clouds and sudden rainfall. When the sun rises, the ambient relative humidity declines gradually and keeps to a minimum value of $55 \%$ at around noon. This corresponds to the maximum temperature of $36{ }^{\circ} \mathrm{C}$. The ambient temperature during nighttime reaches about $22{ }^{\circ} \mathrm{C}$, while the relative humidity increases to $88 \%$. 

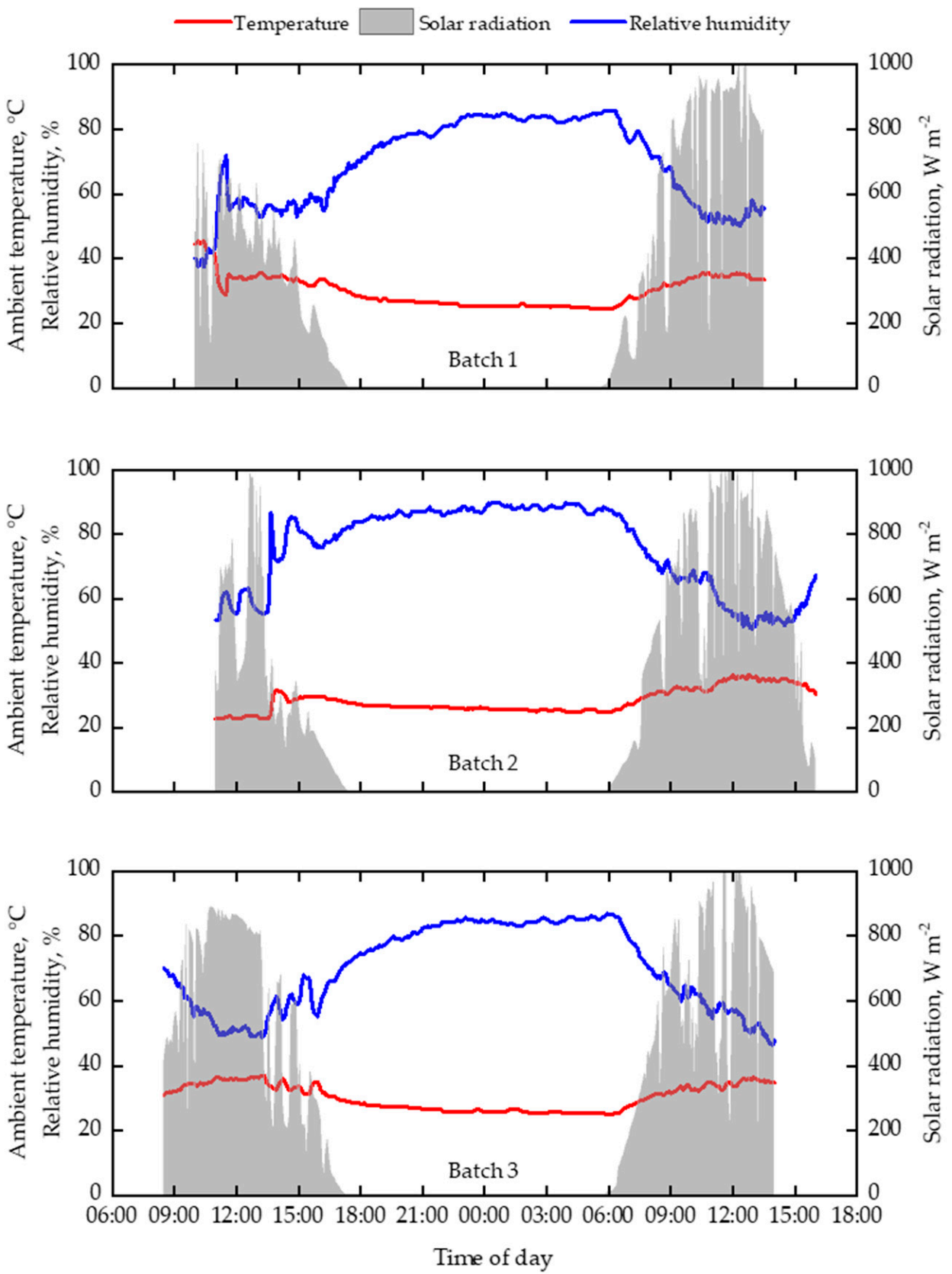

Figure 10. The variation of ambient temperature, relative humidity, and solar radiation for the three experimental batches during rainy season.

The simulated temperature was validated against the experimental paddy rice data, as shown in Figure 11. It can be observed that the temperature increase in the drying area was well reproduced throughout the drying process. During the daytime, the average drying air temperatures varied from 5 to $25^{\circ} \mathrm{C}$ above the ambient temperature. The highest experimental and simulated drying temperatures were 63.7 and $60.2^{\circ} \mathrm{C}$ at 13:05 and 12:00, respectively. The high fluctuation of weather conditions such as cloudiness or sudden showers influenced the temperature in the ISD. This phenomenon can be also observed from the simulated temperature. Therefore, the simulation was in good agreement with experimental data. 

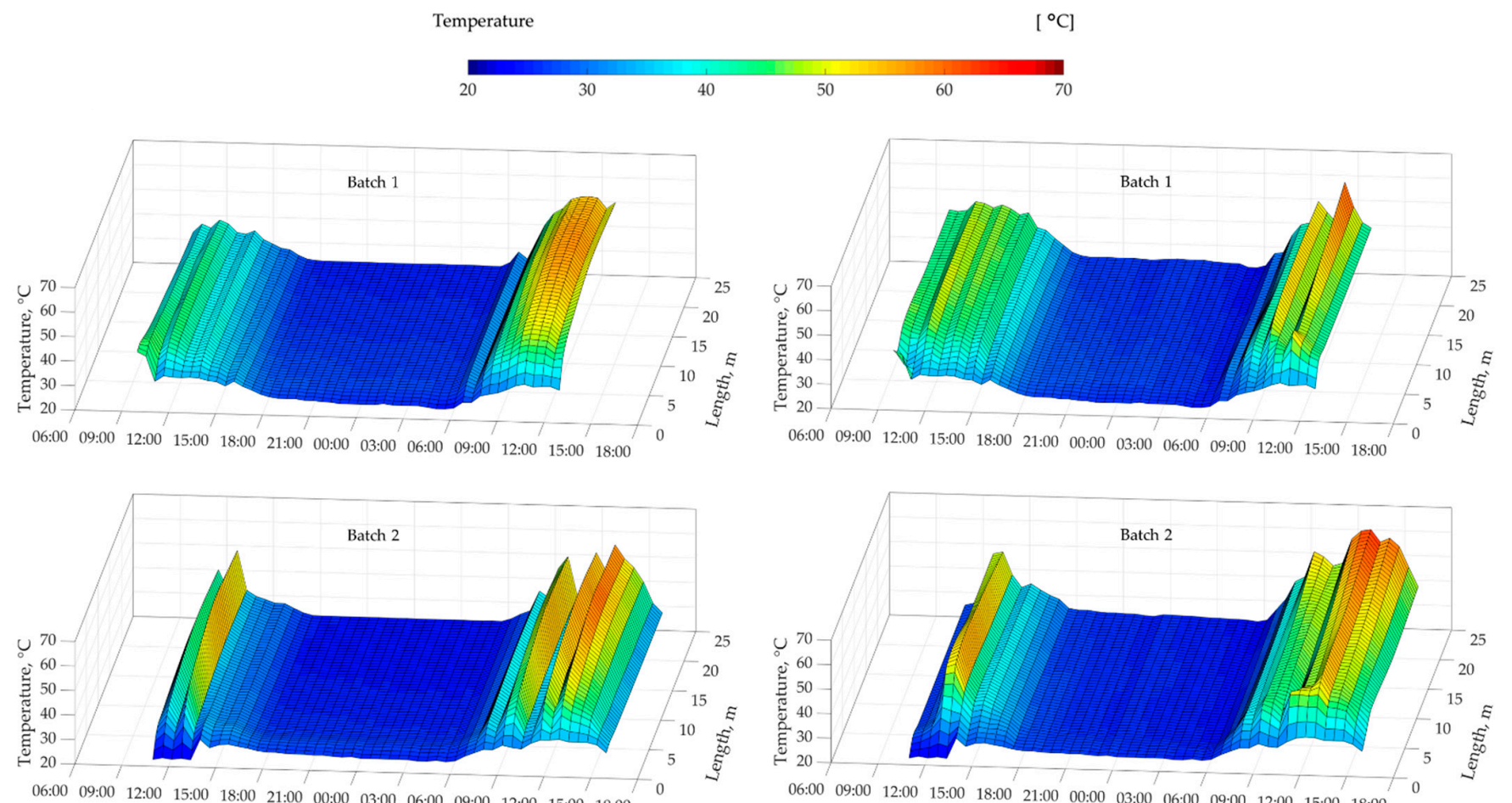

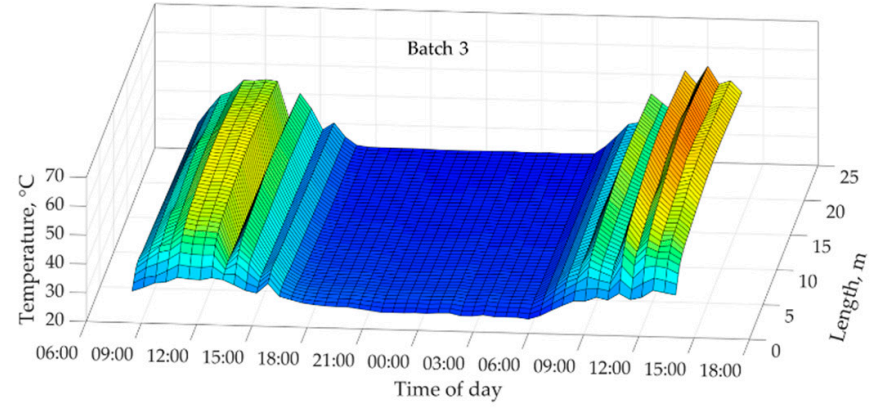

(a)

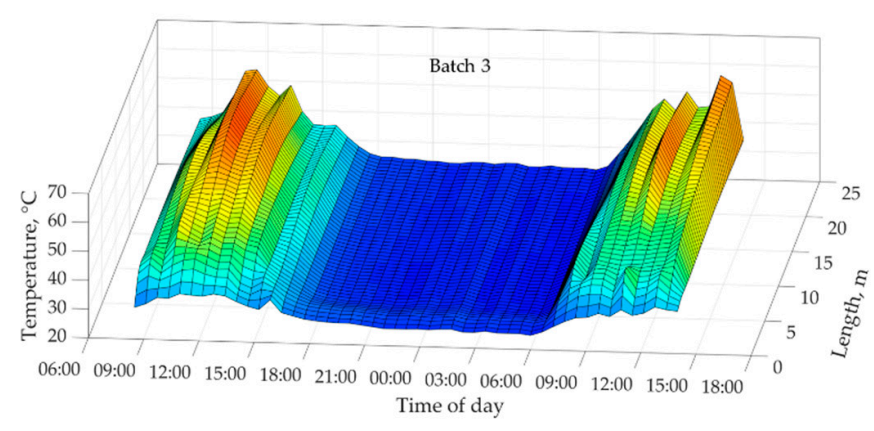

(b)

Figure 11. Simulated (a) and experimental (b) temperature profile over time and along the length of the ISD of the 3 experimental batches.

\subsubsection{Simulation of the Moisture Content during the Drying Process}

Figure 12 shows the comparison between the experimental and predicted moisture contents during solar drying of paddy rice in the ISD. Rewetting during night or rainy hours was not observed as the fans were operating continuously. The target moisture content was reached with the ISD between 27 and $29.5 \mathrm{~h}$ according to the experimental values. From the experimental data, it can be seen that increased fluctuation of weather conditions strongly influences the drying behavior of paddy rice. Nevertheless, the simulation model could effectively predict the moisture content changes during drying, particularly under good weather conditions, as shown in batch 3 .

\subsubsection{Accuracy of the Model}

The goodness of fit of the simulation model is presented in Table 3. High accuracy can be observed from the temperature in the heating area and the outlet, as well as the moisture content of the paddy rice during drying. The highest $\mathrm{R}^{2}$ can be observed from batch 3 where the weather conditions were stable, especially the first day compared to the other batches. For the three batches, the RMSE for temperature was less than $6.6{ }^{\circ} \mathrm{C}$ and $1.4 \%$ for moisture content. In general, the MAPE for temperatures is below $6.9 \%$, while the 
MAPE of moisture content is below 7.4\%. As the MAPE of the simulation model was still below $10 \%$, high prediction accuracy was therefore proven [42].
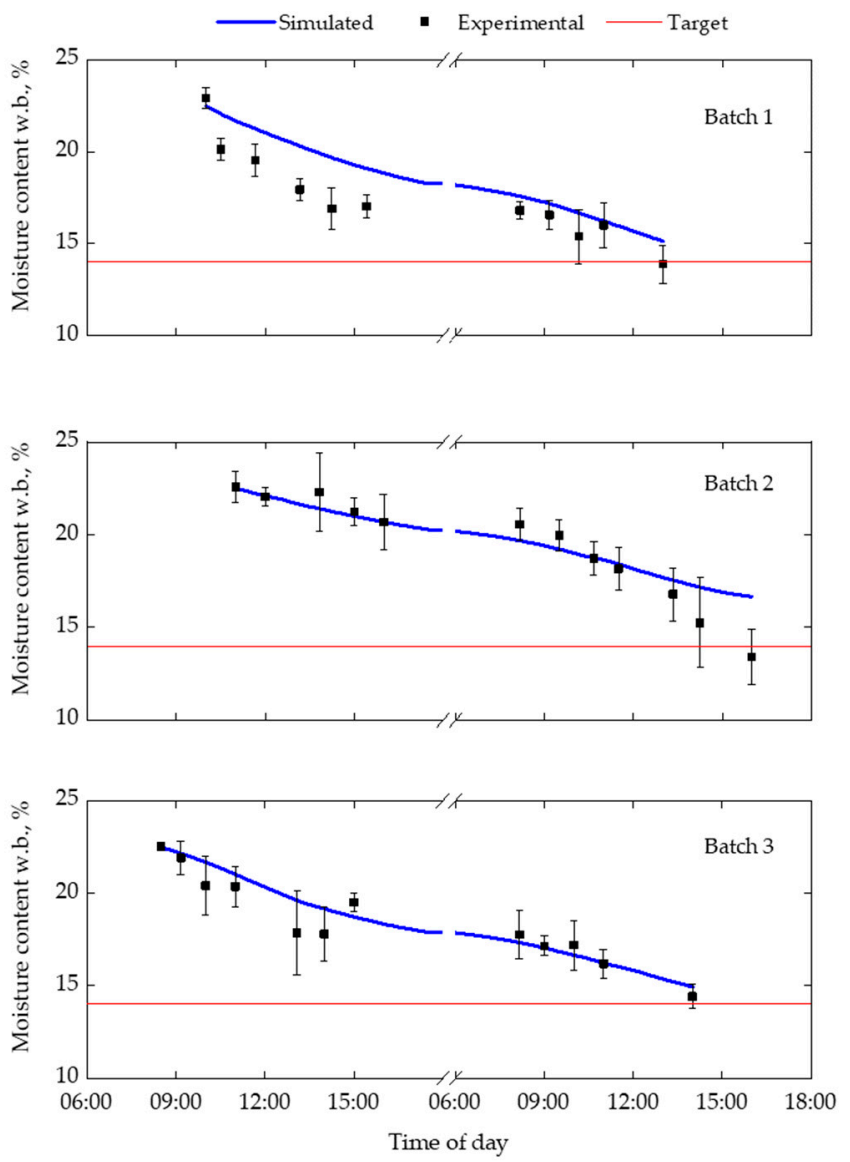

Figure 12. Experimental and simulated moisture content in the ISD during paddy rice drying of three experimental batches (red line indicates target $\mathrm{MC}_{\mathrm{wb}}=14 \%$ ).

Table 3. Model constants and statistic criteria (moisture content wet basis- $M C_{w b}$, coefficient of determination- $\mathrm{R}^{2}$, root mean square error root mean square error-RMSE and the mean absolute percentage error-MAPE).

\begin{tabular}{|c|c|c|c|c|c|c|c|}
\hline Batch & Date & Drying Period h & Initial $M C_{\text {w.b. }} \%$ & Variables & $\mathbf{R}^{2}$ & $\operatorname{RMSE}^{\circ} \mathrm{C}, \%$ & MAPE \% \\
\hline \multirow{3}{*}{1} & \multirow{3}{*}{30 October 2013} & \multirow{3}{*}{27.0} & \multirow{3}{*}{22.3} & $T_{a b s}$ & 0.85 & 2.7 & 1.5 \\
\hline & & & & $T_{\text {pad }}$ & 0.73 & 5.8 & 6.5 \\
\hline & & & & $M C_{w . b}$ & 0.82 & 1.4 & 7.4 \\
\hline \multirow{3}{*}{2} & \multirow{3}{*}{5 November 2013} & \multirow{3}{*}{29.0} & \multirow{3}{*}{22.5} & $T_{a b s}$ & 0.91 & 2.7 & 0.2 \\
\hline & & & & $T_{\text {pad }}$ & 0.79 & 6.6 & 6.3 \\
\hline & & & & $M C_{w . b}$ & 0.84 & 1.2 & 3.1 \\
\hline \multirow{3}{*}{3} & \multirow{3}{*}{15 November 2013} & \multirow{3}{*}{29.5} & \multirow{3}{*}{22.5} & $T_{a b s}$ & 0.90 & 2.2 & 0.4 \\
\hline & & & & $T_{\text {pad }}$ & 0.85 & 5.1 & 6.9 \\
\hline & & & & $M C_{w . b}$ & 0.96 & 0.5 & 0.9 \\
\hline
\end{tabular}

\subsubsection{Application of the Model}

Figure 13a shows the simulated moisture content during the relevant months in the dry season and the rainy season for the 10-year period (2008-2017). Figure $13 \mathrm{~b}$ summarizes the average drying time for the dry season and the rainy season, where $14 \% \mathrm{MC}_{\mathrm{wb}}$ was achieved. The prediction shows that during the dry season, the target moisture content can be reached within $10 \mathrm{~h}$, while during the rainy season, the drying time increases, and the drying time may be higher than $30 \mathrm{~h}$. 


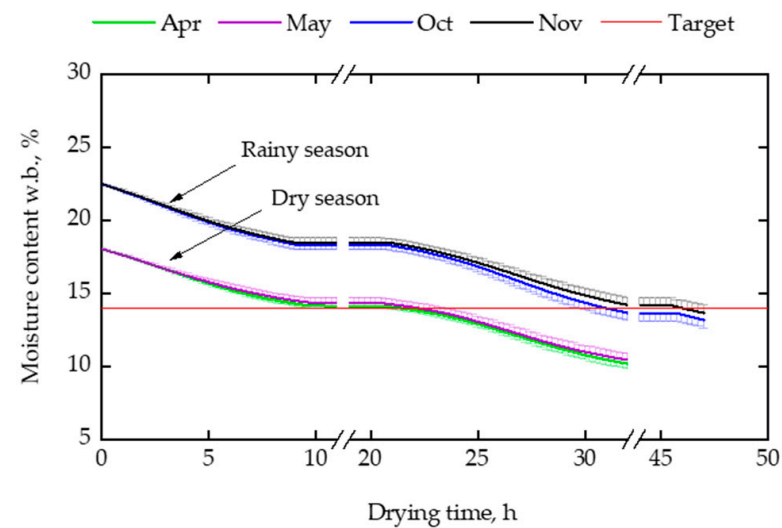

(a)

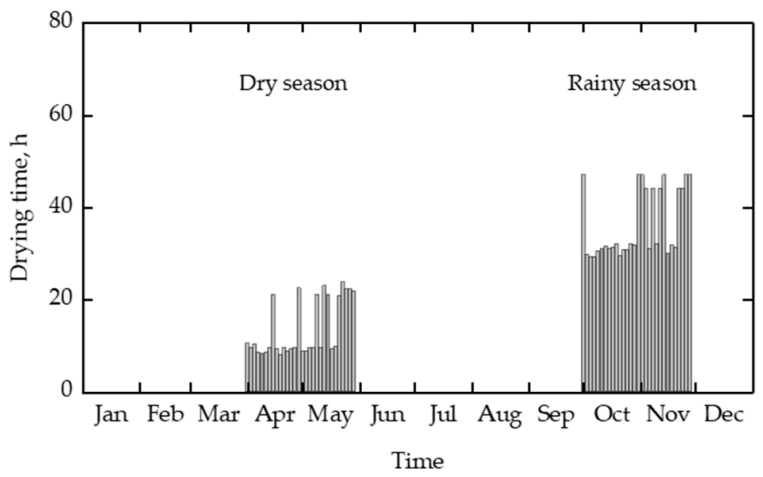

(b)

Figure 13. Simulated outputs of the ISD drying model using the weather data from the experimental station of the International Rice Research Institute in Los Baños, Laguna, Republic of the Philippines (average 2008-2017); (a) drying curves corresponding to the peak harvesting months of the dry season and the rainy seasons and (b) drying time obtained for a target $\mathrm{MC}_{\mathrm{wb}}=14 \%$ from each harvest season.

\section{Discussion}

The current study investigated the airflow patterns in the ISD. The results obtained with the CFD simulation model helped to visualize the airflow distribution (Figure 7). A velocity reduction is expected due to an abrupt expansion from the fan to the dryer. These results are likely to be related to a turbulent regime [43] and generated vortex in the heating area, as seen in Figure 7a. A similar flow structure has been shown in another study [44].

Previous studies evaluating the airflow patterns in solar dryers have been conducted using a CFD approach $[21,45,46]$, where the study of the turbulence effect was proportionally related to the rate of heat transfer. This effect was also observed in the ISD where the presence of higher velocity in the heating area and lower velocities over the paddy rice spread along the drying area shows a temperature rise across the dryer (Figure 11b).

The simulated results from the MATLAB/Simulink model are consistent with the experimental data (Figure 11). A similar behavior was also observed from drying various agricultural products using the Hohenheim solar tunnel dryer type [23,47-50].

Several studies have reported different simulation models of forced convection solar drying systems, where a thin layer of drying materials was commonly assumed and described [22,23,51]. In this study, we have used the same approach and have further developed the drying kinetics of paddy rice. For example, we show that the prediction of moisture content during drying is more accurate compared to the prediction of temperatures (Table 3). Based on the results, the drying process in the ISD can be computationally evaluated with a good agreement to the empirical measurements.

The results of the application of the model over the dry and the rainy seasons further support the results of the previous ISD experiments [16], where drying during the rainy season required a long period of time, while in the dry season it was accomplished within $10 \mathrm{~h}$ of the drying process. Further research should be undertaken with ANSYS fluent and MATLAB/Simulink to investigate the application of the collaborative model approach with different agricultural commodities and weather conditions.

\section{Conclusions}

This study presents CFD-Simulink models used to simulate and predict the ISD's performance when drying paddy rice. The airflow patterns were successfully investigated across the ISD using a CFD approach via ANSYS Fluent. A good agreement was revealed between the CFD simulation and experimental velocity measurements with an $R^{2}$ of 0.78 and RMSE of $0.72 \mathrm{~m} \mathrm{~s}^{-1}$. A variation of air velocity from 5 to $0.5 \mathrm{~m} \mathrm{~s}^{-1}$ and 0.5 to $0.1 \mathrm{~m} \mathrm{~s}^{-1}$ was obtained at the heating and drying area, respectively. A vortex was observed from 3 
to $4 \mathrm{~m}$ in the heating area caused by the air conveyance of the axial fans. Moreover, we successfully modeled the drying process of paddy rice using the MATLAB/Simulink. A good agreement between the experimental and the simulated moisture contents of paddy rice $\left(\mathrm{R}^{2}>0.82\right.$, RMSE $\left.<1.4{ }^{\circ} \mathrm{C}, \mathrm{MAPE}<7.4 \%\right)$ and temperatures $\left(\mathrm{R}^{2}>0.73\right.$, RMSE $<6.6 \%$, MAPE $<6.9 \%$ ) was achieved. The validated model allowed an accurate assessment of the drying behavior of paddy rice over the rainy and dry seasons to be made.

The CFD-Simulink models proved to be an efficient and effective means of simulating and assessing the ISD's performance under different weather conditions. The computational approach used in this study shows great potential as a decision support tool to improve the ISD design. Further investigations should include the mixing effect of paddy rice during drying and the ratio of heating and drying area.

Author Contributions: Conceptualization, A.S.-R. and J.M.; methodology, A.S.-R. and J.M.; software, A.S.-R. and I.R.; validation, A.S.-R.; formal analysis, A.S.-R., I.R., S.R. and J.M.; investigation, A.S.R.; resources, A.S.-R. and J.M.; data curation, A.S.-R.; writing—original draft preparation, A.S.R.; writing-review and editing, A.S.-R., I.R., S.R. and J.M.; visualization, A.S.-R., I.R. and S.R.; supervision, J.M.; project administration, A.S.-R.; funding acquisition, J.M. All authors have read and agreed to the published version of the manuscript.

Funding: This research was made possible through the Global Rice Science Scholarships by International Rice Research Institute (IRRI), grant number 7500RC000000G4102090, Project Funding for International Agricultural Research Centers, GIZ/BMZ, GIZ Project Number: 10.7860.9-001.00, and the scholarships awarded by Fiat Panis Foundation (Ulm, Germany).

Institutional Review Board Statement: Not applicable.

Informed Consent Statement: Not applicable.

Data Availability Statement: Not applicable.

Acknowledgments: The authors would like to thank Martin Gummert, Eduardo Secretario, Elenita C. Suñaz, Caling Balingbing, Grace Centeno, Eugenio Aquino and Denis Diaz from IRRI, Sabine Nugent for her language editing support, and Marcus Nagle for assisting in the development of the ISD together with the colleagues from GrainPro Philippines Inc. Tom de Bruin, Zaida Manglicmot Salim, Marvin Tala, Romimar Corporal, and Dennis Bardolaza.

Conflicts of Interest: The authors declare no conflict of interest.

\section{Nomenclature}

$b \quad$ Width of the ISD design, $\mathrm{m}$

$C_{i} \quad$ Thermal capacity of the material, $\mathrm{J} \mathrm{m}^{-3} \mathrm{~K}^{-1}$

$c_{\text {vap }} \quad$ Specific heat of water vapor, $\mathrm{J} \mathrm{kg}^{-1} \mathrm{~K}^{-1}$

$c_{\text {liq }} \quad$ Specific heat of liquid, $\mathrm{J} \mathrm{kg}^{-1} \mathrm{~K}^{-1}$

$c_{\text {pad }} \quad$ Specific heat of paddy rice, $\mathrm{J} \mathrm{kg}^{-1} \mathrm{~K}^{-1}$

$c_{\text {air }} \quad$ Specific heat capacity of air, $\mathrm{J} \mathrm{kg}^{-1} \mathrm{~K}^{-1}$

$c_{a b s} \quad$ Specific heat capacity of absorber, $\mathrm{J} \mathrm{kg}^{-1} \mathrm{~K}^{-1}$

$c_{\text {asp }} \quad$ Specific heat capacity of asphalt, $\mathrm{J} \mathrm{kg}^{-1} \mathrm{~K}^{-1}$

$c_{s o i} \quad$ Specific heat capacity of soil, $\mathrm{J} \mathrm{kg}^{-1} \mathrm{~K}^{-1}$

$d_{k} \quad$ Kernel diameter, $\mathrm{mm}$

$D_{h} \quad$ Hydraulic diameter of the heating/drying area, $\mathrm{m}$

$g \quad$ Gravity acceleration, $\mathrm{m} \mathrm{s}^{-2}$

$h_{w} \quad$ Convective heat transfer coefficient due to wind, $\mathrm{W} \mathrm{m}^{-2} \mathrm{~K}^{-1}$

$h_{c, \text { cov-air }} \quad$ Convective heat transfer coefficient from the cover to the drying air, $\mathrm{W} \mathrm{m}^{-2} \mathrm{~K}^{-1}$

$h_{c, a b s-a i r} \quad$ Convective heat transfer coefficient from the absorber floor to the drying air, $\mathrm{W} \mathrm{m}^{-2} \mathrm{~K}^{-1}$

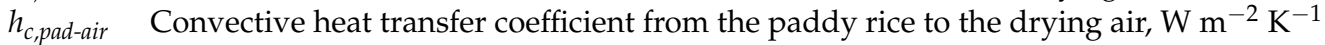

$h_{r, \text { cov-sky }} \quad$ Radiative heat transfer coefficient from the cover to the sky, $\mathrm{W} \mathrm{m}{ }^{-2} \mathrm{~K}^{-1}$

$h_{r, a b s-c o v}$ Radiative heat transfer coefficient from the absorber to the cover, $\mathrm{W} \mathrm{m}^{-2} \mathrm{~K}^{-1}$

$h_{r, p a d-c o v}$ Radiative heat transfer coefficient from the paddy rice to the cover, $\mathrm{W} \mathrm{m}^{-2} \mathrm{~K}^{-1}$

$H \quad$ Humidity ratio of air, $\mathrm{kg} \mathrm{kg}^{-1}$

$I_{t} \quad$ Solar radiation, $\mathrm{W} \mathrm{m}^{-2}$ 
$K_{\text {abs-asp }}$ Thermal conductance from the absorber to the asphalt, $\mathrm{kJ} \mathrm{m}^{-2} \mathrm{~s}^{-1}$

$K_{\text {pad-abs }}$ Thermal conductance from the paddy rice to the absorber, $\mathrm{kJ} \mathrm{m}^{-2} \mathrm{~s}^{-1}$

$K_{\text {asp-soi }} \quad$ Thermal conductance from the asphalt to soil, $\mathrm{kJ} \mathrm{m}^{-2} \mathrm{~s}^{-1}$

$k \quad$ Drying constant $\mathrm{h}^{-1}$

$L_{c} \quad$ Characteristic length of the geometry, $\mathrm{m}$

$L_{\text {pad }} \quad$ Latent heat of paddy rice, $\mathrm{kJ} \mathrm{kg}^{-1}$

M Moisture content d.b.

Me Equilibrium moisture content d.b.

$\mathrm{Nu} \quad$ Nusselt number

$\mathrm{Pr} \quad$ Prandtl number

$p \quad$ Static pressure, $\mathrm{Pa}$

$p_{\text {atm }} \quad$ Atmospheric pressure, $\mathrm{Pa}$

$p_{s} \quad$ Saturation vapor pressure, $\mathrm{Pa}$

Re Reynolds number

$S_{m} \quad$ Momentum source term, $\mathrm{Pa} \mathrm{m}^{-1}$

$t \quad$ Time, $\mathrm{h}$

$t_{f} \quad$ Final drying time, $\mathrm{h}$

$T_{\text {cov }} \quad$ Temperature of the cover, ${ }^{\circ} \mathrm{C}$

$T_{a b s} \quad$ Temperature of the absorber, ${ }^{\circ} \mathrm{C}$

$T_{\text {pad }} \quad$ Temperature of the paddy rice, ${ }^{\circ} \mathrm{C}$

$T_{\text {air }} \quad$ Temperature of the drying air, ${ }^{\circ} \mathrm{C}$

$T_{\text {sky }} \quad$ Temperature of the sky, ${ }^{\circ} \mathrm{C}$

$T_{\text {amb }} \quad$ Ambient temperature, ${ }^{\circ} \mathrm{C}$

$T_{\text {asp }} \quad$ Temperature of the asphalt, ${ }^{\circ} \mathrm{C}$

$T_{d p} \quad$ Dew point temperature, ${ }^{\circ} \mathrm{C}$

$v_{\text {air }} \quad$ Air velocity, $\mathrm{m} \mathrm{s}^{-1}$

$\vec{v} \quad$ Velocity vector, $\mathrm{m} \mathrm{s}^{-1}$

$\Delta x \quad$ Finite distance, $\mathrm{m}$

Greek letters

$\alpha_{\text {cov }} \quad$ Absorptance of the cover

$\alpha_{a b s} \quad$ Absorptance of the absorber

$\alpha_{\text {pad }} \quad$ Absorptance of the paddy rice

$\varepsilon_{\text {cov }} \quad$ Emittance of the cover

$\varepsilon_{\text {pad }} \quad$ Emittance of the paddy rice

$\varepsilon_{a b s} \quad$ Emittance of the absorber

$\tau_{\text {cov }} \quad$ Transmittance of the cover

$\in \quad$ Porosity of paddy rice

$\rho_{\text {air }} \quad$ Density of air, $\mathrm{kg} \mathrm{m}^{-3}$

$\rho_{a b s} \quad$ Density of absorber, $\mathrm{kg} \mathrm{m}^{-3}$

$\rho_{\text {pad }} \quad$ Density of paddy rice, $\mathrm{kg} \mathrm{m}^{-3}$

$\rho_{a s p} \quad$ Density of asphalt, $\mathrm{kg} \mathrm{m}^{-3}$

$\rho_{\text {soi }} \quad$ Density of soil, $\mathrm{kg} \mathrm{m}^{-3}$

$\rho \quad$ Reflectance

$\lambda_{\text {air }} \quad$ Thermal conductivity of air, $\mathrm{W} \mathrm{m}^{-1} \mathrm{~K}^{-1}$

$\lambda_{a b s} \quad$ Thermal conductivity of absorber, $\mathrm{W} \mathrm{m}^{-1} \mathrm{~K}^{-1}$

$\lambda_{\text {pad }} \quad$ Thermal conductivity of paddy rice, $\mathrm{W} \mathrm{m} \mathrm{m}^{-1} \mathrm{~K}^{-1}$

$\lambda_{\text {asp }} \quad$ Thermal conductivity of asphalt, $\mathrm{W} \mathrm{m}{ }^{-1} \mathrm{~K}^{-1}$

$\lambda_{\text {soi }} \quad$ Thermal conductivity of soil, $\mathrm{W} \mathrm{m}^{-1} \mathrm{~K}^{-1}$

$\sigma \quad$ Stefan-Boltzmann constant, $\mathrm{W} \mathrm{m}^{-2} \mathrm{~K}^{-4}$

$\overline{\bar{\tau}} \quad$ Reynolds stress tensor, $\mathrm{Pa}$

$\theta \quad$ Zenith angle

$v \quad$ Kinematic viscosity, $\mathrm{m}^{2} \mathrm{~s}^{-1}$

$\varphi \quad$ Relative humidity, $\%$

$\mu_{\text {air }} \quad$ Dynamic viscosity of air, $\mathrm{kg} \mathrm{m}^{-1} \mathrm{~s}^{-1}$

$\delta_{\text {air }} \quad$ Thickness of air, $\mathrm{m}$

$\delta_{a b s} \quad$ Thickness of paddy absorber, $\mathrm{m}$

$\delta_{\text {pad }} \quad$ Thickness of paddy rice, $\mathrm{m}$

$\delta_{\text {asp }} \quad$ Thickness of asphalt, $\mathrm{m}$

$\delta_{\text {soi }} \quad$ Thickness of soil, $\mathrm{m}$ 


\section{Appendix A}

According to Bala [35] the radiative heat transfer coefficients are:

$$
\begin{aligned}
& h_{r, p v c-c o v}= \frac{\sigma \cdot\left(T_{a b s}^{2}+T_{c o v}^{2}\right) \cdot\left(T_{a b s}+T_{c o v}\right)}{\frac{1}{\varepsilon_{a b s}}+\frac{1}{\tau_{c o v}}+\frac{1}{1-\tau_{c o v}}-2} \\
& h_{r, p a d-c o v}= \frac{\sigma \cdot\left(T_{p a d}^{2}+T_{c o v}^{2}\right) \cdot\left(T_{p a d}+T_{c o v}\right)}{\frac{1}{\varepsilon_{p a d}}+\frac{1}{\tau_{c o v}}+\frac{1}{1-\tau_{c o v}}-2} \\
& h_{r, c o v-s k y}=\frac{\sigma \cdot\left(T_{c o v}^{2}+T_{s k y}^{2}\right) \cdot\left(T_{c o v}+T_{s k y}\right)}{\frac{1}{\varepsilon_{c o v}}+\frac{1}{\tau_{c o v}}-1}
\end{aligned}
$$

The sky temperature was calculated according to Hossain, et al. [22]:

$$
T_{\text {sky }}=T_{\text {air }} \cdot\left[0.8+\frac{\left(T_{d p}-273\right)}{250}\right]^{1 / 4}
$$

where $T_{d p}$ is the dew point temperature is used from ASHRAE [52]:

$$
T_{d p}=6.54+14.526 \cdot \xi+0.7389 \cdot \xi^{2}+0.09486 \cdot \xi^{3}+0.4569 \cdot\left(\varphi \cdot p_{s}\right)^{0.1984}
$$

where $\xi=\ln \left(\varphi \cdot p_{s}\right)$ and $p_{s}$ is the saturation vapor pressure which is defined as [53]:

$$
p_{s}=\frac{6 \cdot 10^{25}}{\left(273.15+T_{\text {air }}\right)^{5}} \cdot \exp \cdot\left(-\frac{6800}{273.15+T_{\text {air }}}\right)
$$

The humidity ratio according Thorpe [53] is given as:

$$
H=\frac{0.622 \cdot \varphi \cdot p_{s}}{p_{a t m}-\left(\varphi \cdot p_{s}\right)}
$$

The latent heat of vaporization of moisture from the paddy rice according to Bala [35] is given as:

$$
L_{\text {pad }}=2501.61 \cdot(1+23 \cdot \exp (-0.4 \cdot M))
$$

\section{References}

1. Papademetriou, M.K.; Dent, F.J.; Herath, E.M. Bridging the Rice Yield Gap in the Asia-Pacific Region; FAO Regional Office for Asia and the Pacific: Bangkok, Thailand, 2000.

2. GRISP (Global Rice Science Partnership). Rice Almanac. In Source Book for One of the Most Important Economic Activities on Earth, 4th ed.; International Rice Research Institute: Los Baños, Philippines, 2013.

3. Manandhar, A.; Milindi, P.; Shah, A. An overview of the post-harvest grain storage practices of smallholder farmers in developing countries. Agriculture 2018, 8, 57. [CrossRef]

4. Chen, G. Advances in Agricultural Machinery and Technologies, 1st ed.; CRC Press: Boca Raton, FL, USA, 2018.

5. Mopera, L.E. Food Loss in the Food Value Chain: The Philippine Agriculture Scenario. J. Dev. Sustain. Agric. 2016, 11, 8-16. [CrossRef]

6. Abdullah, S.N.A.; Chai-Ling, H.; Wagstaff, C. Crop Improvement: Sustainability through Leading-Edge Technology; Springer International Publishing AG: Cham, Switzerland, 2017.

7. Tsotsas, E.; Mujumdar, A.S. Modern Drying Technology, Volume 3: Product Quality and Formulation; Wiley: Hoboken, NJ, USA, 2011.

8. Ulep, M.C.; Casil, F.B.; Castro, R.C.; Gagelonia, E.C.; Bautista, E.U. Technical and socio-economic evaluation in Ilocos Norte of a low-cost grain dryer from Vietnam. Philipp. J. Crop Sci. 2004, 29, 5-15.

9. Djokoto, I.K.; Maurer, R.; Muehlbauer, W. Solar tunnel dryer for drying paddy. AMA 1989, 20, 41-43.

10. Chupungco, A.; Dumayas, E.; Mullen, J. Two-Stage Grain Drying in the Philippines; ACIAR: Canberra, Australia, 2008 ; p. 50.

11. Romulado, M. Modelling and Simulation of the Two-Stage Rice Drying System in the Philippines. Ph.D. Thesis, Agricultural Engineering University of Hohenheim, Stuttgart, Germany, 2001. 
12. Gummert, M. Improved postharvest technologies and management for reducing postharvest losses in rice. Acta Horticult. 2013, 1011, 63-70. [CrossRef]

13. Rodriguez, A.; Paz, R. Factors affecting the use of mechanical dryers. In Partnerships for Modernizing the Grain Postproduction Sector; Bakker, R., Borlagdan, P., Hardy, B., Eds.; International Rice Research Institute: Los Baños, Philippines, $2004 ;$ pp. 51-56.

14. Cardino, A. Case studies of mechanical dryers in the Philippines: Lessons learned. In Small Farm Equipment for Developing Countries; International Rice Research Institute: Los Baños, Philippines, 1986; pp. 431-437.

15. Maurer, R. Untersuchung Und Modifikation Einer Solaren Tunneltrocknungsanlage Mit Integriertem Kollektor Für Den Einsatz Bei Der Reistrocknung in Humiden Gebieten. Diplom Thesis, Agricultural Engineering University of Hohenheim, Stuttgart, Germany, 1989.

16. Salvatierra-Rojas, A.; Nagle, M.; Gummert, M.; de Bruin, T.; Müller, J. Development of an inflatable solar dryer for improved postharvest handling of paddy rice in humid climates. Int. J. Agric. Biol. Eng. 2017, 10, 269-282. [CrossRef]

17. Romuli, S.; Schock, S.; Somda, M.K.; Müller, J. Drying performance and aflatoxin content of paddy rice applying an inflatable solar dryer in Burkina Faso. Appl. Sci. 2020, 10, 3533. [CrossRef]

18. Romuli, S.; Schock, S.; Nagle, M.; Chege, C.G.K.; Müller, J. Technical performance of an inflatable solar dryer for drying amaranth leaves in Kenya. Appl. Sci. 2019, 9, 3431. [CrossRef]

19. van Hung, N.; Fuertes, L.A.; Balingbing, C.; Roxas, A.P.; Tala, M.; Gummert, M. Development and performance investigation of an inflatable solar drying technology for oyster mushroom. Energies 2020, 13, 4122. [CrossRef]

20. Asemu, A.M.; Habtu, N.G.; Delele, M.A.; Subramanyam, B.; Alavi, S. Drying characteristics of maize grain in solar bubble dryer. J. Food Process Eng. 2020, 43, 3312. [CrossRef]

21. Ghaffari, A.; Mehdipour, R. Modeling and Improving the Performance of Cabinet Solar Dryer Using Computational Fluid Dynamics. Int. J. Food Eng. 2015, 11, 157-172. [CrossRef]

22. Hossain, M.A.; Woods, J.L.; Bala, B.K. Simulation of solar drying of chilli in solar tunnel drier. Int. J. Sustain. Energy 2005, 24, 143-153. [CrossRef]

23. Janjai, S.; Lamlert, N.; Intawee, P.; Mahayothee, B.; Boonrod, Y.; Haewsungcharern, M.; Bala, B.K.; Nagle, M.; Müller, J. Solar drying of peeled longan using a side loading type solar tunnel dryer: Experimental and simulated performance. Dry. Technol. 2009, 27, 595-605. [CrossRef]

24. Esper, A. Solarer tunneltrockner mit photovoltaischem antriebssystem. Ph.D. Thesis, Agricultural Engineering University of Hohenheim, Stuttgart, Germany, 1995.

25. Chen, C. Evaluation of Air Oven Moisture Content Determination Methods for Rough Rice. Biosyst. Eng. 2003, 86, 447-457. [CrossRef]

26. ANSYS. ANSYS FLUENT Theory Guide; ANSYS Inc.: Canonsburg, PA, USA, 2011.

27. Sanghi, A.; Ambrose, R.P.K.; Maier, D. CFD simulation of corn drying in a natural convection solar dryer. Dry. Technol. 2018, 36, 859-870. [CrossRef]

28. Iguaz, A.; San Martín, M.B.; Arroqui, C.; Fernández, T.; Maté, J.I.; Vírseda, P. Thermophysical properties of medium grain rough rice (LIDO cultivar) at medium and low temperatures. Eur. Food Res. Technol. 2003, 217, 224-229. [CrossRef]

29. Lee, C.; Chung, D. Grain physical and thermal properties related to drying and aeration. In Grain Drying in Asia; Champ, B.R., Highley, E., Johnson, G.I., Eds.; Australian Centre for International Agricultural Research: Bangkok, Thailand, 1996 ; p. 410.

30. ANSYS. Cell Zone and Boundary Conditions. In ANSYS Fluent User's Guide. Release 15.0; ANSYS, Inc.: Canonsburg, PA, USA, 2013.

31. ANSYS. User Guide. Available online: https://www.afs.enea.it/project/neptunius/docs/fluent/html/ug/node167.htm (accessed on 15 September 2020).

32. Drück, H.; Mathur, J.; Panthalookaran, V.; Sreekumar, V.M. Green Buildings and Sustainable Engineering: Proceedings of GBSE 2019; Springer: Singapore, 2020.

33. Çengel, Y.A. Heat Transfer: A Practical Approach; McGraw-Hill: New York, NY, USA, 2003.

34. Salvatierra-Rojas, A.; Torres-Toledo, V.; Müller, J. Influence of surface reflection (Albedo) in simulating the sun drying of paddy rice. Appl. Sci. 2020, 10, 5092. [CrossRef]

35. Bala, B.K. Solar Drying Systems: Simulations and Optimization; Agrotech Publishing Academy: Mymensingh, Bangladesh, 1998.

36. Iguaz, A.; Vírseda, P. Moisture desorption isotherms of rough rice at high temperatures. J. Food Eng. 2007, 79, 794-802. [CrossRef]

37. Udomkun, P.; Argyropoulos, D.; Nagle, M.; Mahayothee, B.; Janjai, S.; Müller, J. Single layer drying kinetics of papaya amidst vertical and horizontal airflow. LWT 2015, 64, 67-73. [CrossRef]

38. Crawford, R.J. Plastics Engineering; Elsevier Science: Amsterdam, The Netherlands, 2013.

39. Bai, B.C.; Park, D.W.; Vo, H.V.; Dessouky, S.; Im, J.S. Thermal Properties of Asphalt Mixtures Modified with Conductive Fillers. J. Nanomater. 2015, 2015, 926809. [CrossRef]

40. Campbell, G.S.; Norman, J. An Introduction to Environmental Biophysics; Springer: New York, NY, USA, 2012.

41. Gran, R.J. Numerical Computing with Simulink, Volume 1: Creating Simulations; Society for Industrial and Applied Mathematics: Philadelphia, PA, USA, 2007.

42. Yadav, A.K.; Chandel, S.S. Solar radiation prediction using Artificial Neural Network techniques: A review. Renew. Sustain. Energy Rev. 2014, 33, 772-781. [CrossRef]

43. Burgess, W.A.; Ellenbecker, M.J.; Treitman, R.D. Ventilation for Control of the Work Environment; Wiley: Hoboken, NJ, USA, 2004. 
44. Bournet, P.E.; Boulard, T. Effect of ventilator configuration on the distributed climate of greenhouses: A review of experimental and CFD studies. Comput. Electron. Agric. 2010, 74, 195-217. [CrossRef]

45. Lokeswaran, S.; Eswaramoorthy, M. An experimental analysis of a solar greenhouse drier: Computational Fluid Dynamics (CFD) validation. Energy Sources Part A Recovery Util. Environ. Effects 2013, 35, 2062-2071. [CrossRef]

46. Milczarek, R.R.; Alleyne, F.S. Mathematical and computational modeling simulation of solar drying systems. In Solar Drying Technology; Springer Singapore: Singapore, 2017; pp. 357-379. [CrossRef]

47. Bala, B.K.; Mondol, M.R.A. Experimental investigation on solar drying of fish using solar tunnel dryer. Dry. Technol. 2001, 19, 427-436. [CrossRef]

48. Bala, B.K.; Mondol, M.R.A.; Biswas, B.K.; Das Chowdury, B.L.; Janjai, S. Solar drying of pineapple using solar tunnel drier. Renew. Energy 2003, 28, 183-190. [CrossRef]

49. Schirmer, P.; Janjai, S.; Esper, A.; Smitabhindu, R.; Mühlbauer, W. Experimental investigation of the performance of the solar tunnel dryer for drying bananas. Renew. Energy 1996, 7, 119-129. [CrossRef]

50. Lutz, K.; Mühlbauer, W.; Müller, J.; Reisinger, G. Development of a multi-purpose solar crop dryer for arid zones. Solar Wind Technol. 1987, 4, 417-424. [CrossRef]

51. Bala, B.K.; Woods, J.L. Simulation of the indirect natural convection solar drying of rough rice. Sol. Energy 1994, 53, 259-266. [CrossRef]

52. ASHRAE. Fundamentals Handbook; ASHRAE: Atlanta, GA, USA, 2001.

53. Thorpe, G.R. The application of computational fluid dynamics codes to simulate heat and moisture transfer in stored grains. J. Stored Prod. Res. 2008, 44, 21-31. [CrossRef] 